\title{
System stress testing of bank liquidity risk
}

\author{
Spyros Pagratis*, Nikolas Topaloglou ${ }^{\dagger}$ and Mike Tsionas ${ }^{\ddagger}$
}

December 2016

\begin{abstract}
Using a stress test methodology for bank liquidity risk we estimate the aggregate liquidity shortfall in the U.S. commercial banking system at the height of 2007-09 crisis, identifying key sources of funding vulnerabilities and the dominant composition of liquid asset holdings against liquidity shocks. The largest liquidity shocks to the system are estimated in the first half of the crisis, in line with Acharya and Mora (2015). Large banks experience the largest liquidity shortfall in 2008:Q1 (\$154 billion or 14\% of total assets) and small banks in 2007:Q4 ( $\$ 117$ billion or 11\% of total assets). The dominant funding vulnerability to the system stems from large time deposits, while government securities largely dominate other classes of liquid assets as liquidity backstop. The analysis draws on detailed bank-level data on balance sheet flows of funds and applies stochastic dominance efficiency methods to capture liquidity risk diversification effects across assets and liabilities.
\end{abstract}

JEL classification codes: C14, C44, G11, G18, G21

Keywords: Banks; Liquidity Risk; Stochastic Dominance Efficiency.

\footnotetext{
*Department of Economics, Athens University of Economics and Business, E-mail: spagratis@aueb.gr

${ }^{\dagger}$ Department of International \& European Economic Studies, Athens University of Economics and Business, E-mail: nikolas@aueb.gr

‡Lancaster University Management School, LA1 4YX Uk \& Athens University E.B., Greece, E-mail: tsionas@aueb.gr
} 


\section{Introduction}

Bank liquidity risk stems from the maturity transformation function of turning liquid, shortterm deposits into illiquid, long-term loans. That makes banks susceptible to a bank-run problem à la Diamond and Dybvig. ${ }^{1}$ Liquidity risk crystalizes when banks cannot fully fund their stock of loans due to liquidity demands from foreclosures of funding lines and involuntary asset growth originated off-balance sheet. To self-insure against liquidity shocks, banks hold high quality liquid assets (HQLA) that may swiftly monetize to meet liquidity demands. $^{2}$ The amount of precautionary HQLA holdings required to self-insure against liquidity shocks depends on both the intensity and diversification of cash outflows across the balance sheet. The stronger and more correlated the outflows, the higher the amount of HQLA needed to insure against liquidity risk and vice versa.

Liquidity risk diversification effects arise from synchronized increases in deposit inflows and cash outflows to meet credit demands in periods of market stress. ${ }^{3}$ Before the 2007-09 crisis, deposit-loan synergies was a typical phenomenon allowing banks (especially larger banks) to perform their maturity transformation role and economize on HQLA buffers. ${ }^{4}$ But following the collapse in housing prices and the market for asset back commercial paper (ABCP) in 2007:Q3, U.S. commercial banks experienced a crisis as liquidity providers

\footnotetext{
${ }^{1}$ This problem is exacerbated by the opaqueness of bank assets (Flannery, Kwan and Nimalendran (2004, 2010)) and asymmetric information about asset quality (Rochet and Vives (2004)).

${ }^{2}$ Following the 2007-09 crisis, the Basel Committee on Banking Supervision produced a new set of rules (Basel III) requiring, among other things, banks to hold liquidity buffers of easy-to-sell assets against a crisis similar to that caused by the Lehman collapse.

${ }^{3}$ Systematic correlations across assets and liabilities also arise from standard arbitrage relationships, such as between holding reserve balances with the central bank and the level of secured (repo), or unsecured (Fed funds) borrowing in the interbank market. In normal times, banks tend to arbitrage differences between interbank and policy rates, inducing some positive correlation between reserve balances and interbank lending. But in a stress scenario, interbank-market frictions and concerns about the stigma of tapping non-standard central bank liquidity (discount window) may lead banks to hoard reserves and curtail interbank lending, inducing even negative correlations between reserve balances and interbank lending, or borrowing. This is discussed extensively in Acharya and Merrouche (2013) and Ashcraft, McAndrews and Skeie (2011).

${ }^{4}$ See, for instance, Kashyap and Stein (2000), Kashyap, Rajan, and Stein (2002) Gatev and Strahan (2006), Gatev, Schuermann, and Strahan (2006), Cornett, McNutt, Strahan, and Tehranian (2011), Acharya and Mora (2015).
} 
(Acharya and Mora (2015)). ${ }^{5}$ This was a result of weak deposit growth driven by concerns about bank solvency and the ability of official safety nets to withstand the fallout of the crisis. Following the Lehman failure in 2008Q3, liquidity pressure to U.S. commercial banks abated due to swift reversal in aggregate flows from money market mutual funds into bank deposits, which by then had benefited from extended government guarantees.

In this paper we develop a stress test methodology to estimate the aggregate shortfall of high quality liquid assets (HQLA) in the U.S.-chartered commercial banking system at the height of 2007-09 crisis. We also identify key sources of funding vulnerabilities to the system and the dominant composition of liquid asset holdings against liquidity shocks.

Taking the standpoint of a macro-prudential regulator, we consider systematic foreclosures of funding lines, combined with involuntary asset growth, as the basic source of systemic liquidity risk. This is in the spirit of Allen, Babus and Carletti (2013), noting that funding foreclosures may occur systematically across banks due to information spillovers. They show that the incidence of foreclosures increases in asset commonality across banks, in the opportunity cost of funds, and in bankruptcy costs. All three conditions were met at the onset of the crisis, nourishing a perfect storm of systematic foreclosures in the U.S. commercial banking system. Table 1 shows a high concentration of bank assets in loans secured by real estate, which make up more than half of the average balance sheet. Also, bankruptcy costs increased due to housing market collapse in August 2007, at the same time that the opportunity cost of money market funding hiked following the ABCP market closure (Acharya, Schnabl and Suarez (2013)).

\section{[Table 1]}

The analysis rests on the premise that U.S. commercial banks had entered a deleveraging phase since the onset of 2007-09 crisis, steering clear of voluntarily increases in loan stock. Thus any positive (negative) growth in assets (liabilities) during the crisis - in excess of any

\footnotetext{
${ }^{5}$ Similar evidence is provided by He, Khang, and Krishnamurthy (2010) and Ashcraft, Bech, and Frame (2010).
} 
structured component due to seasonalities and other factors - is assumed to be involuntary and exogenous. Conditioning on a liquidity shock to the system, liquidity risk crystallizes if involuntary cash outflows from asset and liability demands exceed banks' HQLA buffers, in which case the stock of loans cannot be fully funded. We argue this possibility is minimized if the distributional distance between net cash outflows and changes in shareholders' equity is maximized. In other words, liquidity risk is minimized if net cash outflows respect a first-order stochastic dominance (FSD) criterion relative to changes in shareholders' equity.

FSD is a central theme in a variety of applications in economics and finance. It aims at comparing random variables under a common set of preferences by rational decision-makers. Stochastic orderings are binary relations defined on classes of probability distributions. They translate mathematically intuitive ideas like being larger or being more variable for random quantities. Lately, multivariate comparisons have become more popular. Scaillet and Topaloglou (2010) use stochastic dominance efficiency (SDE) tests to compare a given portfolio with a best diversified portfolio of assets. In this paper we follow a similar methodology to select a balance sheet structure (called the SDE balance sheet) that minimizes liquidity risk, taking into account liquidity risk diversification effects across the balance sheet. ${ }^{6}$ The SDE balance sheet implies a HQLA and funding mix that, conditionally on a liquidity shock, makes cash outflows less likely to outpace changes in shareholders' equity, which is used as a benchmark.

We consider a balance sheet split of 10 asset classes and 7 liability classes. Asset classes include 4 loan classes, 5 liquid asset classes, and a residual class of other assets. In particular, liquid asset classes include cash, Fed funds sold and repo, government securities, agency MBS, equities, and other available-for-sale securities. Based on a fair-value loss criterion, we classify as HQLA cash, Fed funds sold and repo, government securities, and agency MBS. Liability

\footnotetext{
${ }^{6}$ Post (2003), Kuosmanen (2004) and Scaillet and Topaloglou (2010) introduce the notion of SDE that extends pairwise stochastic dominance analysis in a portfolio context, allowing for diversification effects. The identified SDE allocation of portfolio weights is also the best allocation according to the first-order stochastic dominance criterion (Hadar and Russel (1969), Bawa (1975)).
} 
classes include Fed funds purchased and repo, 5 deposit classes, and a residual category of other liabilities. Deposit classes include demand deposits, interest bearing transaction deposits, small time deposits (less than $\$ 100,000$ ), large time deposits (more than $\$ 100,000$ ), and a residual class of other deposits.

The proportions (weights) which asset and liability classes enter the SDE balance sheet are selected non-parametrically, avoiding the use of a parametric risk measure or loss function. The SDE criterion rewards asset and liability classes that show low intensity of cash outflows and tend to mitigate liquidity tensions from other parts of the balance sheet. The higher the SDE weight the less likely the respective balance sheet class to generate involuntary cash outflows concurrently with other classes and vice versa. Therefore, SDE weights provide a measure of liquidity contributions. HQLA classes are assigned a high (low) SDE weight if monetization of assets from these classes tends to offset a large (small) proportion of liquidity demands elsewhere on the balance sheet. Similarly, deposit classes are assigned a high (low) SDE weight if funding inflows (outflows) in these classes tend to mitigate (exacerbate) cash outflows.

The aggregate liquidity shortfall in the system is the difference (if positive) between the estimated HQLA buffer implied by the SDE balance sheet and actual HQLA holdings by banks. In other words, the aggregate liquidity shortfall is the extra buffer of HQLA - in addition to actual holdings by banks - needed to best insure full funding of existing stock of loans in the system, taking into account liquidity risk diversification effects across assets and liabilities. By measure of estimated shortfall we compare liquidity shocks through time to determine the largest liquidity shocks to the system during the crisis. Against these shocks, we identify funding vulnerabilities of the system and dominant compositions of precautionary liquid asset holdings.

SDE balance sheets are estimated separately for small and large banks conditionally on aggregate liquidity shocks to the system. To derive proxies for liquidity shocks we exploit large pieces of Call Report data for the period 2002:Q1-2009:Q1 and draw on cross-sectional 
heterogeneity of balance sheet flows across banks. Moreover, to compare liquidity shocks over time we insulate unstructured variability in the flow of funds from structured changes due to seasonalities and individual bank effects. Thus we adjust growth rates in assets and liabilities by taking the residuals of estimated panel regressions on quarter dummies and individual bank fixed effects, removing also possible autocorrelation. As a proxy of the liquidity shock to the system each quarter we use the empirical joint distribution of unstructured components of growth rates in balance sheet classes during the quarter.

Precautionary HQLA buffers are important for banks to perform their maturity transformation role, but they involve an opportunity cost of idle capital as they typically yield lower expected returns than less liquid assets, such as loans. We internalize such a cost in the SDE optimization by adding a profitability constraint that requires the SDE balance sheet to produce expected returns that are higher than or equal to expected returns across the peer group during the sample period. Given that the basic source of profits to banks is interest income, we use net interest margin as a measure of bank profitability. Similarly, SDE balance sheets are constrained to meet a capital adequacy target to internalize the capital charge associated with the choice of balance sheet structure. As a measure of bank capital adequacy we use the Tier-1 capital ratio.

Another constraint to the SDE optimization problem is that banks cannot freely reduce the stock of loans due to loan illiquidity. Therefore, SDE allocations of loan classes are constrained to be greater than or equal to their initial level. That allows liquidity contributions by HQLA and deposit classes to be determined jointly, taking into account possible diversification effects between involuntary loan growth and funding inflows. Moreover, offbalance-sheet exposures may be a significant source of system vulnerability, as noted by Papanikolaou and Wolff (2014). Loan commitments, in particular, may expose banks to significant liquidity risk in periods of market stress. ${ }^{7}$ We implicitly control for the impact

\footnotetext{
${ }^{7}$ For example, U.S. commercial banks honored loan commitments to corporates following significant drawdowns in the second half of August 2007, as documented in Ivashina and Scharfstein (2010), Campello, Giambona, Graham, and Harvey (2011), Berrospide, Meisenzahl, and Sullivan (2012) and Berrospide and
} 
of loan commitments on system liquidity risk by constraining the stock of loans from being reduced, while at the same time the empirical joint distribution of balance sheet flows allows loan growth to be positive, which in a stress scenario is considered as involuntary growth and attributable to commitment drawdowns.

To put things in perspective, consider the average composition of U.S. commercial banks' balance sheet, for the period 2007:Q3-2008:Q2. Table 1 shows that average composition hardly changes during the period, but more action is evident at growth level. Table 2 presents linear correlations and moments of (unstructured) growth rates in assets and liabilities for large banks in 2008:Q1. Growth in loans secured by real estate shows high skewness (3.83) and kurtosis (24.93), implying high liquidity demands from borrowers. At the same time, growth in certain deposit classes is particularly weak. Time deposits (above $\$ 100,000)$ and interest bearing transaction deposits show negative growth rates $(-4 \%)$ and negative skewness, implying high levels of foreclosures. In contrast, other deposits have positive skewness (3.07) and significant correlation with loans secured by real estate (0.34). This indicates that funding inflows in other deposits may compensate for liquidity demands from real estate borrowers. We formalize such comparisons of liquidity contributions using a SDE criterion, considering all possible moments of the empirical joint distribution of balance sheet flows and full diversification effects.

[Table 2]

The results show that the largest liquidity shock to the system occurred in the first half of 2007-09 crisis. Large banks faced it in 2008:Q1, with an estimated HQLA shortfall of $\$ 154$ billion (14\% of total assets). That compares with a shortfall of $\$ 88$ billion ( $8 \%$ of total assets) in 2007:Q4 and \$46 billion (4\% of total assets) in 2008:Q2. Small banks faced the largest shock in 2007:Q4, with an estimated HQLA shortfall of $\$ 117$ billion (11\% of Meisenzahl (2015). 
total assets). Government securities largely dominate all classes of liquid assets as liquidity backstop, and funding vulnerabilities are dominated by weak growth in large time deposits (above the FDIC deposit insurance coverage limit). But since the onset of the crisis, the U.S. commercial banking system appears to have benefitted from government-sponsored borrowing and substantial inflows in time deposits following the increase of the deposit insurance coverage limit. This is consistent with Acharya and Mora (2015), noting that government support was a predominant factor allowing banks to honor their role as liquidity providers during the crisis. Robustness of results is confirmed using alternative specification of the optimization problem, using different sets of constraints. Bootstrapping techniques also confirm the robustness of results to alternative specifications of the underlying distribution of balance sheet flows.

The remainder of the paper is organized as follows. Section 2 explains the basic framework and Section 3 describes the SDE optimization procedure. Section 4 discusses the empirical strategy and data. Section 5 presents the results and Section 6 concludes. A proof is included in the Appendix, and tables and figures are gathered at the end.

\section{Basic framework}

Let bank assets $A_{t}$ funded by debt liabilities $L_{t}$ and equity $E_{t}$ at time $t$. Assets consist of illiquid loans, HQLA and other items, while liabilities are mainly liquid short-term funds, both retail and wholesale. Liquidity risk stems from the possibility that the bank next period $t+1$ is unable to fully fund its assets as a result of involuntary flows in assets or liabilities. The easier to compensate for such flows the lower the liquidity risk and vice versa.

Conditioning on time $t$ and on a stress scenario hitting the system next period $t+1$ any increase in assets $\left(\Delta A_{t+1}\right)^{+}$or reduction in liabilities $\left(\Delta L_{t+1}\right)^{-}$is assumed to be involuntary and exogenous. ${ }^{8}$ Involuntary outflows from asset and liability demands are the basic sources

\footnotetext{
${ }^{8}$ The idea is that amidst adverse shocks banks generally wish not to engage in asset growth or cutting
} 
of liquidity risk, which crystallizes if net outflows $\left(\Delta A_{t+1}-\Delta L_{t+1}\right)$ turn out to be greater than changes in equity $\Delta E_{t+1}$. To minimize such possibility as of time $t$, next-period changes in assets $\Delta A_{t+1}$, liabilities $\Delta L_{t+1}$ and equity $\Delta E_{t+1}$ must preserve the following first-order stochastic dominance $(F S D)$ criterion.

$$
\Delta A_{t+1}-\Delta L_{t+1} \underset{F S D}{\prec} \Delta E_{t+1}
$$

This would be compatible with any strictly monotonic preference of the macroprudential regulator aiming to impose relationship (1), which in terms of conditional probabilities $\mathbf{P}_{t}(\cdot)$ implies

$$
\mathbf{P}_{t}\left(\Delta A_{t+1}-\Delta L_{t+1} \leq x\right) \geq \mathbf{P}_{t}\left(\Delta E_{t+1} \leq x\right) \quad \forall x \in \mathbb{R}
$$

Assets at $t$ are known, therefore dividing both sides in (1) by $A_{t}$ we get

$$
\frac{\Delta A_{t+1}}{A_{t}}-\frac{\Delta L_{t+1}}{A_{t}} \underset{F S D}{\prec} \frac{\Delta E_{t+1}}{A_{t}}
$$

or

$$
\frac{\Delta A_{t+1}}{A_{t}}-\frac{\Delta L_{t+1}}{L_{t}} \frac{L_{t}}{A_{t}} \underset{F S D}{\prec} \frac{\Delta E_{t+1}}{E_{t}} \frac{E_{t}}{A_{t}}
$$

Given that assets are fully funded by debt liabilities $L_{t}$ and equity $E_{t}$ at time $t$ (i.e. $\left.A_{t}=L_{t}+E_{t}\right)$ substituting $L_{t}=A_{t}-E_{t}$ in (4) we obtain

$$
\frac{\Delta A_{t+1}}{A_{t}}-\frac{\Delta L_{t+1}}{L_{t}} \frac{A_{t}-E_{t}}{A_{t}} \underset{F S D}{\prec} \frac{\Delta E_{t+1}}{E_{t}} \frac{E_{t}}{A_{t}}
$$

which in terms of next period growth rates in assets $g_{t+1}^{A}=\frac{\Delta A_{t+1}}{A_{t}}$, liabilities $g_{t+1}^{L}=\frac{\Delta L_{t+1}}{L_{t}}$ and equity $g_{t+1}^{E}=\frac{\Delta E_{t+1}}{E_{t}}$, adjusted for current leverage $l e v_{t}=A_{t} / E_{t}$, becomes

$$
g_{t+1}^{A}-g_{t+1}^{L}\left(1-\frac{1}{l e v_{t}}\right) \underset{F S D}{\prec} g_{t+1}^{E} \frac{1}{l e v_{t}}
$$

down their funding lines voluntarily. Instead, they would aim to delever by reducing assets or increasing equity, while preserving their funding lines. 
or

$$
g_{t+1}^{A} l e v_{t}+g_{t+1}^{L}\left(1-l e v_{t}\right) \underset{F S D}{\prec} g_{t+1}^{E}
$$

The stochastic dominance criterion (7) compares conditional distributions of growth rates in assets and liabilities with that of growth rates in equity that is used as benchmark. Let $w_{t, A}^{i}$ be the proportion of total assets allocated in asset class $i$ and $w_{t, L}^{j}$ the proportion of total liabilities allocated in liability class $j$. Let also $g_{t+1, A}^{i}$ and $g_{t+1, L}^{j}$ be the growth rates in the respective asset and liability classes over the next period. Liquidity risk is minimized for the balance sheet allocation that satisfies the FSD criterion (7), taking into account liquidity risk diversification effects across all asset classes $i$ and liability classes $j$, as follows.

$$
\sum_{i} w_{t, A}^{i}\left[-g_{t+1, A}^{i} l e v_{t}\right]+\sum_{j} w_{t, L}^{j}\left[g_{t+1, L}^{j}\left(l e v_{t}-1\right)\right] \underset{F S D}{\succ}-g_{t+1}^{E}
$$

where $w_{t, A}^{i}, w_{t, L}^{j} \geq 0$ and $\sum_{i} w_{t, A}^{i}=\sum_{j} w_{t, L}^{j}=1$.

Before we solve for the optimization problem, we discuss profitability, capital adequacy, and loan illiquidity constraints that liquidity optimal allocations must also respect.

\subsection{Profitability constraint}

In order to select SDE weights for asset and liability classes we consider their impact on expected profitability. Given that interest income is the main source of income for commercial banks, as a profitability metric we use the net interest margin (nimar), defined as the ratio of net interest income (interest income minus interest expense) to total assets. We assume 
the following mapping from asset and liability weights $w_{t, A}^{i}, w_{t, L}^{j}$ into net interest margin. ${ }^{9}$

$$
\operatorname{nimar}_{t+1}=\beta_{0}+\sum_{i} \beta_{i} G_{t+1, A}^{i} w_{t, A}^{i}+\sum_{j} \gamma_{j} G_{t+1, L}^{j} w_{t, L}^{j}+\varepsilon_{t+1}
$$

where, $G_{t+1, A}^{i}$ and $G_{t+1, L}^{j}$ are gross growth rates in the stock of asset and liability classes, $\beta_{0}$, $\beta_{i}, \gamma_{j}$ are fixed coefficients, and $E\left(\varepsilon_{t+1}\right)=0$.

Equation (9) implies loadings for asset (liability) classes equal to coefficients $\beta_{i}\left(\gamma_{j}\right)$ times the respective growth rates $G_{t+1, A}^{i}\left(G_{t+1, L}^{j}\right)$. These loadings capture the opportunity cost of holding liquid assets and the relative cost of liabilities. The implied mapping of balance sheet weights into net interest margin is assumed known to the macroprudential regulator and can be inferred from cross-sectional heterogeneity across banks, as discussed in Section 5. Estimating (9) and assuming rational expectations about mean growth rate in assets $\bar{G}_{A}^{i}$ and liabilities $\bar{G}_{L}^{j}$, we get the following profitability constraint to the SDE problem for balance sheet weights $w_{t, A}^{i}, w_{t, L}^{j}$.

$$
\widehat{\beta}_{0}+\sum_{i} \widehat{\beta}_{i} \bar{G}_{A}^{i} w_{t, A}^{i}+\sum_{j} \widehat{\gamma}_{j} \bar{G}_{L}^{j} w_{t, L}^{j} \geq \text { profitability target }
$$

where, $\widehat{\beta}_{0}, \widehat{\beta}_{i}, \widehat{\gamma}_{j}$ are estimated coefficients from a cross sectional regression presented in Section 5, and profitability target refers to mean net interest margin across banks. ${ }^{10}$

\footnotetext{
${ }^{9}$ Let turnover $Y_{t+1}$ from assets $A_{t+1}^{i}$ and liabilities $L_{t+1}^{j}$ be given by a Cobb-Douglas production $Y_{t+1}=$ $C_{t+1} \prod_{i}\left(A_{t+1}^{i}\right)^{\beta_{i}} \prod_{j}\left(L_{t+1}^{j}\right)^{\gamma_{j}}$. Assuming perfect competition and decreasing returns to scale, the return of each balance sheet class is equal to its marginal product and net interest income $n i i_{t+1}$ is given by $n i i_{t+1}=\left(1-\sum_{i} \beta_{i}-\sum_{j} \gamma_{j}\right) Y_{t+1}$. Dividing both sides by total assets at time $t$ and expressing asset and liability classes at $t+1$ as stock at $t$ times the respective gross growth rate, the first-order Taylor approximation of nimar $_{t+1}$ is the deterministic counterpart of (9).

${ }^{10}$ We also experimented with alternative profitability metrics, such as the return on assets (roa), and profitability targets, such as the upper 25th percentile of the nimar distribution. However, the results remain broadly unchanged.
} 


\subsection{Capital adequacy constraint}

Banks also face capital constraints, both due to regulatory rules and market discipline. Capital constraints are usually defined as minimum ratios of some measure of bank equity to risk-weighted assets. Minimum capital ratios depend on asset composition that affects risk weighted assets in the denominator. But may also depend on the funding mix and extent to which equity is considered sufficient for the bank to access certain sources of funding, such as insured deposits. As a metric for bank capital adequacy we consider the ratio of Tier1 capital to risk-weighted assets $\left(\right.$ tier $\left.1_{t+1}\right)$. We assume the following mapping from asset weights $w_{t, A}^{i}$ and liability weights $w_{t, L}^{j}$ into Tier1 capital ratio.

$$
\operatorname{tier} 1_{t+1}=\delta_{0}+\sum_{i} \delta_{i} G_{t+1, A}^{i} w_{t, A}^{i}+\sum_{j} \theta_{j} G_{t+1, L}^{j} w_{t, L}^{j}+\eta_{t+1}
$$

where, $G_{t+1, A}^{i}$ and $G_{t+1, L}^{j}$ are gross growth rates in the stock of asset and liability classes, $\delta_{0}$, $\delta_{i}, \theta_{j}$ are fixed coefficients, and $E\left(\eta_{t+1}\right)=0$.

Similar to the profitability constraint, estimating (11) and assuming rational expectations about mean growth rate in assets $\bar{G}_{A}^{i}$ and liabilities $\bar{G}_{L}^{j}$, we get the following capital adequacy constraint to the SDE problem for balance sheet weights $w_{t, A}^{i}, w_{t, L}^{j}$.

$$
\widehat{\delta}_{0}+\sum_{i} \widehat{\delta}_{i} \bar{G}_{A}^{i} w_{t, A}^{i}+\sum_{j} \widehat{\theta}_{j} \bar{G}_{L}^{j} w_{t, L}^{j} \geq \text { capital target }
$$

where, $\widehat{\delta}_{0}, \widehat{\delta}_{i}, \widehat{\theta}_{j}$ are estimated coefficients from a cross sectional regression presented in Section 5, and capital target refers to mean Tier1 capital ratio. ${ }^{11}$

\footnotetext{
${ }^{11}$ As with the profitability constraint, we experimented with alternative capital adequacy targets such as the median and the upper 25th percentile of the cross-sectional distribution of Tier1 capital ratio. Nevertheless, the results remained qualitatively unchanged.
} 


\subsection{Loan-illiquidity constraints}

Loan illiquidity implies that banks cannot freely reduce the stock of loans, which may even rise as a result of credit-line drawdowns by customers. Therefore, SDE weights for loan classes are constrained to be greater than or equal to their initial level.

$$
w_{t, A}^{i} \geq w_{t-1, A}^{i} \text {, for every loan class }
$$

That allows to determine liquidity contributions by HQLA and deposit classes, while taking into account possible diversification effects between involuntary loan growth (e.g. due to credit-line takedowns) and other balance sheet items, such as various classes of deposits. Next we discuss the SDE optimization methodology.

\section{The optimization problem}

In this section we describe the stochastic dominance framework that identifies the optimal balance sheet allocations $w_{t, A}^{i}$ and $w_{t, L}^{j}$ that satisfy relationship (8).

\subsection{Stochastic dominance efficiency}

SDE offers a unified framework to capture diversification effects and liquidity risk contributions among various assets and liabilities. It is an extension of the typical pair-wise stochastic dominance by allowing full diversification and is able to address questions such as which asset and liability class contributes more, or less, to bank liquidity risk.

We consider a process $\boldsymbol{X}_{A, L, s}$ taking values in $\mathbb{R}^{n}$, where $n$ is the total number of balance sheet items that we consider. The observations are a realization of $\left\{\boldsymbol{X}_{A, L, s}, s=1, \ldots, S\right\}$, where $S$ is the number of banks in the system. That corresponds to our data of observed growth rates in assets $g_{t+1}^{A}$ and liabilities $g_{t+1}^{L}$ at time $t+1$, adjusted for current bank leverage $l e v_{t}$, i.e. $g_{t+1}^{A} l e v_{t}, g_{t+1}^{L}\left(l e v_{t}-1\right)$. Let $F(x)$ be the cumulative distribution function of $\boldsymbol{X}$. 
Let us consider an allocation of asset classes $\mathbf{w}_{\mathbf{t}, \mathbf{A}}$ and liability classes $\mathbf{w}_{\mathbf{t}, \mathbf{L}}$, such that $\mathbf{w}_{\mathbf{t}, \mathbf{A}} \geq \mathbf{0}, \mathbf{w}_{\mathbf{t}, \mathbf{L}} \geq \mathbf{0}$ and $\mathbf{e}^{\prime} \mathbf{w}_{\mathbf{t}, \mathbf{A}}=\mathbf{e}^{\prime} \mathbf{w}_{\mathbf{t}, \mathbf{L}}=\mathbf{1}$, with $\mathbf{e}$ being a vector of ones. This means that all the asset and liability classes have non-negative weights that sum to one. Let also $G\left(z, \mathbf{w}_{\mathbf{t}, \mathbf{A}}, \mathbf{w}_{\mathbf{t}, \mathbf{L}} ; F\right)$ denote the cdf of minus assets growth plus liabilities growth $\sum_{i} w_{t, A}^{i}\left(-g_{t+1, A}^{i} l e v_{t}\right)+\sum_{j} w_{t, L}^{j}\left(g_{t+1, L}^{j}\left(l e v_{t}-1\right)\right)=\mathbf{e}^{\prime} \boldsymbol{X}_{A, L, s}\left(-\mathbf{w}_{\mathbf{t}, \mathbf{A}}^{\prime}, \mathbf{w}_{\mathbf{t}, \mathbf{L}}^{\prime}\right)^{\prime}$, at point $z$ given by

$$
G\left(z, \mathbf{w}_{\mathbf{t}, \mathbf{A}}, \mathbf{w}_{\mathbf{t}, \mathbf{L}} ; F\right):=\int_{\mathbb{R}^{n}} \mathbb{I}\left(\mathbf{e}^{\prime} \boldsymbol{X}_{A, L, s}\left(-\mathbf{w}_{\mathbf{t}, \mathbf{A}}^{\prime}, \mathbf{w}_{\mathbf{t}, \mathbf{L}}^{\prime}\right)^{\prime} \leq z\right) d F(u)
$$

The cdf of the benchmark is given by

$$
G\left(z, g_{t+1, E} ; F\right):=\int_{\mathbb{R}} \mathbb{I}\left(-g_{t+1, E} \leq z\right) d F(u)
$$

According to the FSD criterion, the optimally diversified allocation of assets and liabilities is the one with the smallest possible cdf below that of the benchmark, that is

$$
G\left(z, \mathbf{w}_{\mathbf{t}, \mathbf{A}}, \mathbf{w}_{\mathbf{t}, \mathbf{L}} ; F\right) \leq G\left(z, g_{t+1, E} ; F\right)
$$

or,

$$
\int_{\mathbb{R}^{n}} \mathbb{I}\left(\mathbf{e}^{\prime} \boldsymbol{X}_{A, L, s}\left(-\mathbf{w}_{\mathbf{t}, \mathbf{A}}^{\prime}, \mathbf{w}_{\mathbf{t}, \mathbf{L}}^{\prime}\right)^{\prime} \leq z\right) d F(u) \leq \int_{\mathbb{R}} \mathbb{I}\left(-g_{t+1, E} \leq z\right) d F(u)
$$

Therefore, the supervisor selects asset and liability weights $w_{t, A}^{i}$ and $w_{t, L}^{j}$ that maximize the following objective function

$$
\sup _{z, \mathbf{w}_{\mathbf{t}, \mathbf{A}}, \mathbf{w}_{\mathbf{t}, \mathbf{L}}}\left[\int_{\mathbb{R}} \mathbb{I}\left(-g_{t+1, E} \leq z\right) d F(u)-\int_{\mathbb{R}^{n}} \mathbb{I}\left(\mathbf{e}^{\prime} \boldsymbol{X}_{A, L, s}\left(-\mathbf{w}_{\mathbf{t}, \mathbf{A}}^{\prime}, \mathbf{w}_{\mathbf{t}, \mathbf{L}}^{\prime}\right)^{\prime} \leq z\right) d F(u)\right]
$$

subject to the constraints described above. 


\subsection{SDE optimization approach}

The SDE model tests whether there is a linear combination of growth rates in assets and liabilities that dominates the growth in equity with respect to the first stochastic dominance criterion. When the objective value in (18) is positive then there is at least one combination of asset and liability classes that dominates the benchmark. The methodology yields all balance sheet allocations, ranked from best to worst, that dominate the benchmark. The mathematical formulation of the constrained optimization problem is as follows

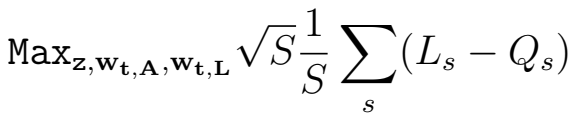

$$
\begin{aligned}
& \text { s.t. } M\left(L_{s}-1\right) \leq z-\left(-g_{t+1, E}^{s}\right) \leq M L_{s} \quad, \forall s \\
& M\left(Q_{s}-1\right) \leq z-\mathbf{e}^{\prime} \boldsymbol{X}_{A, L, s}\left(-\mathbf{w}_{\mathbf{t}, \mathbf{A}}^{\prime}, \mathbf{w}_{\mathbf{t}, \mathbf{L}}^{\prime}\right)^{\prime} \leq M Q_{s} \quad, \forall s \\
& \widehat{\beta}_{0}+\sum_{i} \widehat{\beta}_{i} \bar{G}_{A}^{i} w_{t, A}^{i}+\sum_{j} \widehat{\gamma}_{j} \bar{G}_{L}^{j} w_{t, L}^{j} \geq \text { profitability target } \\
& \widehat{\delta}_{0}+\sum_{i} \widehat{\delta}_{i} \bar{G}_{A}^{i} w_{t, A}^{i}+\sum_{j} \widehat{\theta}_{j} \bar{G}_{L}^{j} w_{t, L}^{j} \geq \text { capital target } \\
& w_{t, A}^{i} \geq w_{t-1, A}^{i} \text {, for every loan class } \\
& \sum_{i} w_{t, A}^{i}=1, \sum_{j} w_{t, L}^{j}=1 \\
& w_{t, A}^{i} \geq 0, w_{t, L}^{j} \geq 0, \forall i, j \\
& Q_{s} \in\{0,1\}, L_{s} \in\{0,1\} \quad, \quad \forall s
\end{aligned}
$$

This is a mixed integer program that maximizes the distance between the sum over all banks of two binary variables, $\frac{1}{S} \sum_{s} L_{s}$ and $\frac{1}{S} \sum_{s} Q_{s}$ which represent the empirical part of $\int_{\mathbb{R}} \mathbb{I}\left(-g_{t+1, E} \leq z\right) d F(u)$ and $\int_{\mathbb{R}^{n}} \mathbb{I}\left(\mathbf{e}^{\prime} \boldsymbol{X}_{A, L, s}\left(-\mathbf{w}_{\mathbf{t}, \mathbf{A}}^{\prime}, \mathbf{w}_{\mathbf{t}, \mathbf{L}}^{\prime}\right)^{\prime} \leq z\right) d F(u)$, respectively. According to (19b), $L_{s}$ equals 1 for each scenario $s$ for which $z \geq-g_{E}^{s}$, and 0 otherwise, and $M$ is a large constant. Similarly, (19c) ensure that $Q_{s}$ equals 1 for each scenario for which 
$z \geq \mathbf{e}^{\prime} \boldsymbol{X}_{A, L, s}\left(-\mathbf{w}_{\mathbf{t}, \mathbf{A}}^{\prime}, \mathbf{w}_{\mathbf{t}, \mathbf{L}}^{\prime}\right)^{\prime}$ and 0 otherwise. (19d) and (19e) are the profitability and capital adequacy constraints and (19f) are the loan illiquidity constraints. Equations (19g) require the sum of all asset and liability weights to be equal to one, while inequality (19h) disallows negative weights. Finally, (19i) defines the binary nature of variables $Q_{s}$ and $L_{s}$.

This is a difficult problem to solve since it involves a large number of binary variables. In order to speed up the estimation we reformulate the problem to make it tractable. For that we need the following.

Proposition 3.1 The optimal value of $z$ belongs to the finite set $\mathcal{R}=\left\{r_{1}, \ldots, r_{S}\right\}$.

Proof. : See Appendix.

A direct consequence of Proposition (3.1) is that we can solve the original problem by solving the smaller problems $P(r), r \in \mathcal{R}$, in which $z$ is fixed to $r$. Then we take the value for $z$ that yields the best total result. The advantage is that the optimal values of the $L_{t}$ variables are known in $P(r)$. Precisely, $\sum_{s} L_{s}$ is equal to the number of $s$ such that $-g_{t+1, E}^{s} \leq r$. Moreover, the factor $\sqrt{S} / S$ can be left out in the objective function, since $S$ is fixed. Hence maximization problem (15) is transformed into the following minimization problem, with constraints (20c-20g) corresponding to (19d-19h) respectively: 


$$
\begin{aligned}
& \min \sum_{s} Q_{s} \\
& \text { s.t.M }\left(Q_{s}-1\right) \leq z-\left(\mathbf{e}^{\prime} \boldsymbol{X}_{A, L, s}\left(-\mathbf{w}_{\mathbf{t}, \mathbf{A}}^{\prime}, \mathbf{w}_{\mathbf{t}, \mathbf{L}}^{\prime}\right)^{\prime}\right) \leq M Q_{s}, \forall s \\
& \widehat{\beta}_{0}+\sum_{i} \widehat{\beta}_{i} \bar{G}_{A}^{i} w_{t, A}^{i}+\sum_{j} \widehat{\gamma}_{j} \bar{G}_{L}^{j} w_{t, L}^{j} \geq \text { profitability target } \\
& \widehat{\delta}_{0}+\sum_{i} \widehat{\delta}_{i} \bar{G}_{A}^{i} w_{t, A}^{i}+\sum_{j} \widehat{\theta}_{j} \bar{G}_{L}^{j} w_{t, L}^{j} \geq \text { capital target } \\
& w_{t, A}^{i} \geq w_{t-1, A}^{i}, \text { for every loan class } \\
& \sum_{i} w_{t, A}^{i}=1, \sum_{j} w_{t, L}^{j}=1 \\
& w_{t, A}^{i} \geq 0, w_{t, L}^{j} \geq 0, \forall i, j \\
& Q_{s} \in\{0,1\}, \forall s
\end{aligned}
$$

The computational time for this mixed integer programming formulation is significantly reduced. For the optimal solution (which involves at most 198 mixed integer optimization programs, one for each discrete value of $z$ ) it takes less than two hours. The problems are optimized with IBM's OSL solver on an iMac computer with a $4^{*} 2.93 \mathrm{GHz}$ Power, $8 \mathrm{~Gb}$ of RAM. We note that the solution time increases exponentially with the number of observations. ${ }^{12}$

\section{Empirical strategy}

We draw on an initial dataset from the Reports of Condition and Income (Call Reports) that covers all U.S. commercial banks for the period 2002:Q1-2009:Q1. The sample period is constrained by confidentiality restrictions in reporting and our objective to achieve maximum

\footnotetext{
${ }^{12}$ The optimizations are modelled using the General Algebraic Modeling System (GAMS). It consists of a language compiler and integrated high-performance solvers. GAMS is tailored for complex, large scale modeling applications. The OSL solver uses the branch and bound technique to solve the MIP program.
} 
possible detail in the classification of balance sheet items.

\subsection{Liquidity shocks}

For each quarter of 2007-09 crisis, we derive a proxy of the liquidity shock to the system by drawing on cross-sectional heterogeneity in stock growth of balance sheet classes across banks. To compare liquidity shocks across quarters we insulate unstructured variability in growth rates from structured variability due to seasonalities and individual bank effects. Therefore, growth rates in balance sheet classes are adjusted by taking the residuals of estimated panel regressions on quarter dummies and individual bank fixed effects over the sample period (2002:Q1-2009:Q1), including also autoregressive components AR( $k$ ) to remove possible autocorrelation. As a proxy of the liquidity shock to the system each quarter we use the empirical joint distribution of estimated residuals $(u)$ of dynamic panel regressions of the form ${ }^{13}$

$$
g_{i, t}=\sum_{k} \rho_{k} g_{i, t-k}+\sum_{j} \beta_{j} \text { quarter }_{j}+v_{i}+\widetilde{u}_{i, t}
$$

where, $g_{i, t}$ is stock growth in a given balance sheet class of bank $i$ in quarter $t, \rho_{k}$ are autoregressive coefficients, quarter $_{j}$ are quarter dummies, $v_{i}$ is fixed effect, and $\widetilde{u}_{i, t}$ is the unstructured component of stock growth.

\subsection{Balance sheet structure and data}

We split assets and liabilities into 17 balance sheet classes in total. This is the finest split we could obtain given Call Report confidentiality restrictions and limited popularity of certain

\footnotetext{
${ }^{13}$ These are estimated separately for small and large banks. The number of autoregressive lags is selected to eliminate autocorrelation in panel data, based on Wooldridge test, and to produce the most parsimonious model on the basis of BIC criterion. To deal with endogeneity problems due to the existence of lagged dependent variables and fixed effects, we instrument lagged growth rates by their lagged differences using standard Arellano-Bond type instruments, i.e. allowing each quarter to occupy a separate column in the weighting matrix. The validity of overidentifying restrictions is checked using the standard Sargan-Hansen test.
} 
items that often take zero values. On the asset side, we consider 4 loan categories of real estate loans (asset class 2), commercial and industrial loans (asset class 3), loans to individuals (asset class 4) and other loans (asset class 5). Liquid assets include cash, Fed funds sold and reverse repo (asset class 1) and the 4 categories of available-for-sale (AFS) securities. These are government securities (asset class 6), agency MBS (asset class 7), equities (asset class 8), and other AFS securities (asset class 9). Other tangible assets (asset class 10) are defined as residual category. On the liability side, we consider Fed funds purchased and repo (liability class 1), demand deposits (liability class 2), interest bearing transaction deposits, such as NOW, ATS, telephone and preauthorized transfer accounts (liability class 3 ), time deposits less than $\$ 100,000$ (liability class 4), time deposits more than $\$ 100,000$ (liability class 5), other deposits (liability class 6), and a residual category of other liabilities (liability class 7).

Given the possibility of internal capital markets operating within multi-bank holding companies (BHC), we focus on bank holding companies instead of individual commercial banks. ${ }^{14}$ To obtain BHC data we sum across banks with same five-digit code (id_rssdHH1) assigned to the principle holding company or the highest holding company in a tiered organization. We follow that route instead of drawing on FR Y-9C reporting forms in order to achieve the finest possible split of asset and liability classes, while obtaining a number of banks sufficient enough to accommodate data requirements of the SDE optimization procedure. ${ }^{15}$ Following the aforementioned consolidation process for individual bank Call Report data, we obtain an original sample of 146,016 quarterly BHC observations from 6,221 banks. For every quarter, we categorize banks into two size categories, small and large, relative to the 95th percentile of the distribution of tangible total assets. Moreover, to avoid growth rates that are due to bank mergers and acquisitions we drop observations $(2,249)$ for which the number of banks within the $\mathrm{BHC}$ is different from the previous quarter.

For variables that often report with zero value - such as Fed funds and repos - growth rate

\footnotetext{
${ }^{14}$ For example, Holod and Peek (2010) find evidence of the existence of internal capital markets within multi-BHCs that allow banks to offset liquidity shocks from monetary policy decisions.

${ }^{15}$ A similar data consolidation approach for deriving BHC data is used by Holod and Peek (2010).
} 
is defined as zero if both the current and lagged level is zero, otherwise reported missing. As a result of calculating growth rates, introducing lags in (21) to obtain unstructured components, and dropping observations with missing values in unstructured growth rates for any of the 17 balance sheet classes, we obtain a final sample of 5,328 quarterly observations (2,973 observations for small banks and 2,355 for large bank) from 483 banks (277 small banks and 206 large banks).

The whole sample for the period 2002:Q1-2009:Q1 is utilized for purposes of estimating the unstructured component of stock growth in assets and liabilities in (21) and reduced-form econometric models for the profitability and capital adequacy constraints (19d) and (19e). For SDE optimization, we use the empirical joint distribution of unstructured growth rates each quarter of the period 2007:Q1-2009:Q1. For that period, the maximum number of large (small) banks is 75 (122) and appears in 2009:Q1 (2008:Q3), and the minimum number is 61 (100) and appears in 2008:Q2 (2007:Q1). Next we discuss further adjustments and data limitations.

\subsection{Flow of funds and stock adjustments}

Before taking growth rates in loans we adjust the stock of each loan category adding back the corresponding quarterly charge-offs, reduced by any recoveries. That is because the book value of loans declines when charge-off are reported on loans, which could create a false sense of inflow similar to loan sales or loan repayments.

Moreover, available-for-sale securities are subject to changes in asset valuations that directly impact on bank equity capital. Therefore, changes in reported figures may not only reflect changes in the flow of securities (i.e. purchases or monetization) but also changes in fair values. In order to account for valuation effects - and not misinterpret them as flow effects - we approximate flows in AFS securities by the growth rate in their amortized cost. At the same time, we account for the impact of valuation changes on bank equity capital 
by adding in (subtracting from) equity the amount of unrealized gain (loss) on available-forsale securities. The growth rate in adjusted bank equity capital across banks is then used as benchmark to the SDE optimization problem.

\subsection{HQLA and data limitations}

Liquid assets classified as HQLA must preserve fair values upon sale in periods of market stress, without compromising banks' capital position. As a measure of fair value change of liquid securities we consider the quarterly growth rate in the ratio of fair-value to amortized cost, where the denominator (amortized cost) controls for changes in stock. According to this measure, equities (asset class 8) and other AFS securities (asset class 9) experienced fair value losses several times higher than government securities (asset class 6) and agency MBS (asset class 7) during the 2007-09 crisis, as shown in Table 3. Therefore, we exclude equities and other AFS securities from HQLA, including only cash, Fed funds sold and repo, government securities, and agency MBS.

[Table 3]

Moreover, the consolidation method that we apply to derive BHC data assumes that liquid assets held at a sub-consolidated level are freely available to the consolidated entity and not subject to regulatory, legal, tax, or other restrictions. Similarly, the cash category includes, inter alia, central bank reserves, which we assume can be freely draw down and not limited by central bank policies. Also, securities may have been pledged or contractually restricted in the process of banks accessing secured funding (e.g. through repos). In line with Basel III rules for liquidity buffers, we should consider only unencumbered securities as eligible for monetization in the calculation of SDE balance sheets, i.e. excluding pledged securities from liquid assets. Although this is possible for the total stock of securities, Call Reports confidentiality precludes identification of unencumbered government securities, 
ABS, equities and other AFS securities. As a result, SDE weights for HQLA in the analysis may underestimate those of unencumbered HQLA.

Finally, Basel III rules do not specify HQLA as available-for-sale, held-to-maturity, or trading securities. But, the vast majority of securities holdings in the data are classified as available-for-sale, which means that considering held-to-maturity or trading securities as separate asset classes would largely reduce the sample due to missing values. Therefore, among government securities and agency MBS, we only consider available-for-sale securities as HQLA, while held-to-maturity and trading securities are included in the residual category of other tangible assets.

\section{Results}

We estimate SDE balance sheets separately for small and large banks. This is because liquidity contributions and appropriate levels of HQLA buffers may differ depending on bank size. Small banks, for example, may require higher HQLA buffers due to frictions and higher costs of accessing uninsured wholesale funding (Kashyap and Stein 2000). Larger banks, by contrast, may need lower precautionary holdings of liquid assets due to easier access to wholesale funding markets and offering a safe haven for investors in periods of market stress (Gatev and Strahan 2006, Gatev et al. 2006). Moreover, the tiered structure of money-market activities and payment systems implies that large banks face the extra task of top-down liquidity provision from the central bank into the banking system, which exposes them to different types of liquidity risks than small banks (Acharya and Merrouche 2013, Ashcraft et al. 2011).

\subsection{Reduced form profitability and capital adequacy}

The profitability and capital constraints (19d) and (19e) are determined by reduced-form models that map balance sheet allocations into profitability and capital ratios. However, the 
opportunity cost of holding liquid assets may be time-varying and affected by cyclical responses of banks to aggregate shocks. ${ }^{16}$ To avoid such cyclical fluctuations affecting the SDE optimization problem, the profitability constraint is based on a fixed mapping that we derive in two steps as follows: First, drawing on Call Report data for the period 2002:Q1-2009:Q1, we estimate panel regressions of net interest margin and balance sheet allocations on quarter dummies and individual bank fixed effect, obtaining the prediction part of each regression as the respective variable's fixed component. Second, the profitability constraint is obtained from the estimated cross-sectional regression of fixed component for net interest margin on the fixed components of balance sheet allocations. The same approach is followed to derive the capital adequacy constraint, based on fixed components of balance sheet allocations and Tier-1 capital ratio. ${ }^{17}$

Estimated coefficients of the reduced-form models for profitability and capital adequacy are shown in Tables 4 and 5 , respectively. ${ }^{18}$ Multiplying the coefficients by the respective mean stock growth in asset and liability classes we derive loadings for the profitability and capital constraints. These are shown in the last two columns of Tables 4 and 5 in bold, with profitability and capital targets shown at the bottom. Estimated loadings have almost identical signs for both sized banks, but differ in terms of statistical and economic significance due to systematic differences in balance sheet compositions and business focus.

[Table 4]

\footnotetext{
${ }^{16}$ Gersbach and Rochet (2012) note that banks respond aggressively to aggregate shocks by reallocating capital without internalizing the impact of their decisions on asset prices. As a result, fluctuations in asset returns become excessively procyclical, amplifying the inherent fragility of banking institutions.

${ }^{17}$ Formulating constraints to the SDE optimization problem on the basis of fixed components of bank metrics is consistent with regulatory practice to calibrate regulatory parameters infrequently and not in response to cyclical fluctuations. It is also consistent with internalizing interactions of policy instruments, avoiding unintended consequences of regulation on bank incentives to accumulate precautionary buffers against adverse shocks due to the impact on bank profits (see, for example, De Nicolo et al. (2014) and Mankart et al. (2015)).

${ }^{18}$ Diagnostic tests for multicollinearity find a high condition index for agency MBS (asset class 7) and other deposits (liability class 6), thus dropped from both constraints.
} 
[Table 5]

Regarding the profitability constraint, small banks receive more negative loadings than large banks for Fed funds and repo (liability class 1), large time deposits (liability class 5), and other deposits (liability class 7), as small banks may face higher costs of accessing wholesale funding. Also a marginal increase in loan weights for small banks implies a higher increase in net interest margin, thus higher loading of loans in the profitability constraint. Finally, small banks seem to have a higher target for net interest margin than large banks, possibly due to higher dependence of small banks' core profitability on net interest income. This is supported by the fact that balance sheet allocations are more informative about the net interest margin of small banks (adjusted $R^{2}: 54 \%$ ) compared to large banks (adjusted $\left.R^{2}: 38 \%\right)$.

For the capital adequacy constraint, the capital adequacy target turns out to be higher for small banks as they tend to have higher Tier 1 capital ratios than large banks. Both sized banks seem to receive comparable capital charges for any marginal increase in weights of real estate loans (asset class 2) and commercial \& industrial loans (asset class 3). Large banks receive a higher capital charge on loans to individuals (asset class 4) and other loans (asset class 5), while small banks receive a higher capital charge on other AFS securities (asset class 9).

\subsection{Liquidity shocks and HQLA shortfall}

In line with Acharya and Mora (2015), we find evidence that the largest liquidity shortfall to the U.S. commercial banking system occurred in the first half of 2007-09 crisis, driven by weak deposit growth. Large banks seem to experience the largest shock in 2008:Q1 and small banks a quarter earlier, in 2007:Q4. This is shown in Figure 1, illustrating actual HQLA ratios (solid line) and estimated ones based on SDE balance sheets (dashed line), for large and small banks. The liquidity shortfall is the difference between SDE-estimated and actual 
HQLA ratios, if positive.

[Figure 1]

In particular, the estimated liquidity shortfall for large banks peaks at $\$ 154$ billion (14\% of total assets) in 2008:Q1, compared to $\$ 88$ billion (8\% of total assets) in 2007:Q4 and $\$ 46$ billion (4\% of total assets) in 2008:Q2. For small banks, it peaks at $\$ 117$ billion (11\% of total assets) in 2007:Q4. This is also confirmed by bootstrapped standard errors for SDE-estimated HQLA ratios (shown in diamonds), which we discuss further in Section 5.4.

Figure 1 also shows estimated SDE weights by HQLA class (in bars), providing a measure of liquidity contributions. Liquid asset classes are assigned a high (low) SDE weight if monetization of assets from these classes tends to offset a large (small) proportion of liquidity demands from assets and liabilities. Government securities receive the highest SDE weight, indicating the highest liquidity contribution among HQLA classes as liquidity shocks to the system peak. In other words, as liquidity conditions in the system worsen, monetization of government securities seem to offer significant liquidity support for banks to perform their maturity transformation role. The second highest SDE weight is assigned to cash, Fed funds sold and repo, indicating that drawing down on cash reserves and interbank exposures turns out to be a line of defense against liquidity shocks. This is particularly true for large banks in the run up to full-blown liquidity shocks. Interestingly, large banks seem to abstain from selling agency MBS to meet liquidity demands, as indicated by the virtually zero SDE weighting for agency MBS up until 2009:Q1.

Table 6 offers more detail on SDE optimization results for all balance sheet classes, conditional on the largest liquidity shocks to the U.S. commercial banking system. Notice that loans (asset classes 2-5) receive relatively high SDE weights due to loan illiquidity constraint. Thus loan weights are not indicative of liquidity contributions, although diversification effects with other balance sheet classes are taken into account to determine SDE weights for 
liquid assets and liability classes.

\section{[Table 6]}

As already shown, government securities are assigned the highest SDE weight among HQLA and other liquid assets. Especially for the stress quarter 2008:Q1 (2007:Q4) government securities are assigned a very high weight of 0.34 (0.29) for large (small) banks. Given that asset weights sum to one, such a high weighting of government securities nearly exhausts all available space in the balance sheet in excess of illiquid loans. This is indicative of the intensity of full-blown liquidity shocks to the system and a crisis of banks as liquidity providers, in line with Acharya and Mora (2015). In other words, during the largest liquidity shocks of 2007-09 crisis, the U.S. commercial banking system seems to have exhausted its ability to self-insure against the shocks through precautionary liquidity holdings. In that case, official-sector intervention to preserve banks' liquidity-provision role in the aggregate might have been indispensable.

This result is robust to alternative specifications of the optimization problem (19a), with or without the profitability constraint (19d) and the capital adequacy constraint (19e). Table 7 presents estimated SDE balance sheets under alternative sets of constraints, conditionally on the liquidity shocks during the 2007:Q4 and 2008:Q1 stress scenarios for small and large banks, respectively. We observe that SDE weights for asset classes, and HQLA in particular, remain almost unaltered under alternative sets of constraints.

[Table 7]

Next we investigate further the nature of liquidity shocks by discussing SDE weights and liquidity contributions on the liability side. 


\subsection{Liquidity contributions of bank deposits}

SDE weights for liability classes are presented in Table 6, measuring funding-liquidity contributions. A liability class receives a high (low) weight if funding inflows (outflows) in this class tend to mitigate (exacerbate) cash outflows from other balance sheet classes. In the run up to Lehman failure, weak growth in large time deposits (more than $\$ 100,000$ ) appears as a dominant source of funding vulnerability for U.S. commercial banks. This is indicated by the zero SDE weight for large deposits, both for large and small banks. Note that large time deposits were exceeding the FDIC deposit insurance coverage limit until early 2008:Q4 when the U.S. Congress raised it from $\$ 100,000$ to $\$ 250,000$. Interestingly, SDE weights for large time deposits turned strongly positive in 2008:Q4 following the increase in deposit insurance coverage. $^{19}$

Moreover, U.S. commercial banks appear to benefit substantially from funding inflows in the residual class of other deposits, as implied by the high SDE weighting. For example, other deposits receive a weighting of 0.35 (0.31) for large (small) banks in 2008:Q1 (2007:Q4) when they face the largest liquidity shock. This is possibly because they include advances from Federal Home Loan Banks and government-sponsored borrowing directed to cover liquidity demands from off-balance sheet exposures in the first half of the crisis, as documented in Ashcraft, Bech, and Frame (2010).

The above findings are consistent with Acharya and Mora (2015), noting that government support was a predominant factor allowing banks to honor their role as liquidity providers during the crisis. Following the Lehman failure in 2008Q3, liquidity pressure to U.S. commercial banks abated due to a reversal in aggregate flows from money market mutual funds into the safe haven of bank deposits, which benefited from extended government guarantees. This reversal is mainly reflected in small time deposits of large banks that receive SDE

\footnotetext{
${ }^{19} \mathrm{SDE}$ optimization results for 2008:Q4 assign a significant weight to large time deposits of $0.27(0.12)$ for small (large) banks. These results are omitted from Table 2 due to space limitations, focusing instead on the period 2007:Q3-2008:Q2 where we identify the largest liquidity shocks to the system, as discussed in Section 5.2. SDE optimization results for the period 2008:Q3-2009:Q1 are available from the authors upon request.
} 
weighting 0.32 and 0.42 for 2008:Q3 and 2008:Q4, respectively. For small banks the reversal of funding flows into small time deposits is less evident, as the SDE weighting remains zero both in 2008:Q2 and 2008:Q3, and increases to 0.15 in 2008:Q4.

Moreover, funding-liquidity contributions implied by SDE weights are robust to alternative specification of the optimization problem, with or without the profitability or the capital adequacy constraint. Table 7 shows estimated SDE weights for liabilities under alternative sets of constraints, conditionally on 2007:Q4 and 2008:Q1 stress scenarios for small and large banks, respectively. We observe that small time deposits (liability class 4) and other deposits (liability class 6) receive the highest SDE weight for small banks, regardless of constraints. Other deposits also receive the highest SDE weight for large banks. But time deposits above the deposit insurance coverage limit (liability class 5) attract zero weighting, both for small and large banks. This is consistent with the view that official-sector safety nets were possibly indispensable at the height of the crisis, enabling U.S. commercial banks to honor their maturity transformation role.

Next we examine whether the relative ordering of liquidity contributions is preserved when applying bootstrapping techniques to calculate SDE weights.

\subsection{Bootstrapping results}

SDE weights depend on the underlying distribution of flows in assets and liabilities. To ensure robustness of our results to alternative specifications of the underlying distribution we rely on a bootstrapping method. This is based on the assumption that the initial sample is representative and the empirical distribution function is a nonparametric estimate of the population distribution. In particular, we draw random samples with replacement from the initial data, separately for small and large banks, maintaining the same sample size as the initial sample. For each bootstrap sample we solve the optimization problem and obtain SDE weights for asset and liability classes. We repeat this procedure 300 times and derive 
the distribution of SDE weights each quarter.

Figure 1 shows bootstrapped standard errors (in diamonds) of SDE-estimated HQLA ratios. They confirm the relative magnitude of liquidity shocks, with the largest shock to large banks occurring in 2008:Q1 and to small banks in 2007:Q4. Figure 2 presents the interquartile range of bootstrapped SDE weights for HQLA (outliers shown in dots), focusing on 2007:Q4 and 2008:Q1 stress scenarios for small and large banks, respectively. The more advanced to the right the interquartile range for a given HQLA class, the more monetization of assets from this class tends to offset liquidity demands from asset and liabilities, and vice versa. Bootstrapping results confirm that, among HQLA holdings, government securities provide the most important liquidity backstop to U.S. commercial banks at the height of the liquidity crisis. They also confirm that drawing down on cash reserves and interbank exposures is a line of defence against large liquidity shocks, but very limited in scope compared to liquidating government securities holdings. It is also confirmed that monetization of agency MBS played almost no role in releasing liquidity to banks during the largest liquidity shock episodes.

[Figure 2]

Figure 3 illustrates the interquartile range of bootstrapped SDE weights for deposit classes. The more advanced to the right the interquartile range for a given deposit class, the more funding inflows in this class tend to mitigate cash outflows from other balance sheet classes and vice versa. Bootstrapping results confirm that the dominant source of funding vulnerability for U.S. commercial banks at the height of the liquidity crisis was large time deposits, i.e. above the FDIC deposit insurance coverage limit. It is also confirmed that U.S. commercial banks benefited substantially from funding inflows in the residual class of other deposits, and to a lesser extent from small time deposits, demand deposits, and interest bearing transaction accounts.

[Figure 3] 


\section{Conclusions}

Systematic foreclosures of funding lines and involuntary asset growth are the basic sources of liquidity risk in the banking system. Taking a macro-prudential standpoint we develop a stress test methodology to gauge liquidity risk in the U.S.-chartered commercial banking system at the height of 2007-09 crisis. We find that liquidity risk crystalized in the first half of the crisis, challenging banks' ability to fully fund their stock of loans from own resources. During the largest liquidity-shock episodes we find that government securities largely dominated all other classes of liquid assets as liquidity backstop. Also, funding vulnerabilities mostly associated with weak growth in large time-deposits, i.e. above the FDIC deposit insurance coverage limit.

The results offer supporting evidence that government intervention was a predominant factor that allowed the U.S. commercial banking system to honor its maturity transformation role during the crisis. Especially for the stress scenarios of 2007:Q4 and 2008:Q1, we show that the amount of government securities required to self-insure from the ensuing liquidity shock would be more than $30 \%$ of system assets. This basically exhausts all available space in bank balance sheets beyond illiquid loans, which is indicative of the intensity of liquidity shocks in a crisis of banks as liquidity providers. In other words, at the height of the

liquidity crisis, U.S. commercial banks appear to have exhausted the ability to self-insure against liquidity shocks, implying that the lender of last resort functions of the official sector was possibly indispensable. 


\section{Appendix}

Proof of Proposition 3.1: Values of $\left(-g_{t+1, E}^{s}\right)$ being given, we can rank them by increasing order. Let $r_{1}, \ldots, r_{S}$ possible different values of $\left(-g_{t+1, E}^{s}\right)$, with $r_{1}<\ldots<r_{S}$. Now, for any $z$ such that $r_{i} \leq z \leq r_{i}+1, \sum_{s} L_{s}$ is constant (i.e. equal to the number of $s$ such that

$\left.-g_{t+1, E}^{s} \leq r_{i}\right)$. Further, when $r_{i} \leq z \leq r_{i}+1$, the maximum value of $-\sum_{s} Q_{s}$ is reached for $z=r_{i}$. Hence, we can restrict $z$ to belong to the set $\mathcal{R}$.

\section{References}

[1] Acharya, V.V., and O. Merrouche. 2013. Precautionary Hoarding of Liquidity and Interbank Markets: Evidence from the Subprime Crisis. Review of Finance, 17(1), 107-60

[2] Acharya, V.V., and N. Mora. 2015. A Crisis of Banks as Liquidity Providers. Journal of Finance, 70(1), 1-43.

[3] Acharya, V.V., P.Schnabl, and G. Suarez. 2013. Securitization without risk transfer. Journal of Financial Economics, 107(3), 515-536.

[4] Allen, F., A. Babus, and E. Carletti. 2012. Asset commonality, debt maturity and systemic risk. Journal of Financial Economics, 104(3), 519-534.

[5] Ashcraft. A.B., J. McAndrews, and D. Skeie. 2011. Precautionary Reserves and the Interbank Market. Journal of Money, Credit and Banking, 43(2), 311-48.

[6] Ashcraft, A.B., M.L. Bech, and W.S. Frame. 2010. The Federal Home Loan Bank System: The Lender of Next-to-Last Resort?. Journal of Money, Credit and Banking, 42(2), 551-83.

[7] Bawa, V. 1975. Optimal Rules for Ordering Uncertain Prospects. Journal of Financial Economics, 2, 95-121. 
[8] Berrospide, J. M., and R. Meisenzahl. 2015. The Real Effects of Credit Line Drawdowns. Finance and Economics Discussion Series, Federal Reserve Board of Governors 2015-007.

[9] Berrospide, J. M., R. Meisenzahl, and B. Sullivan. 2012. Credit line use and availability in the financial crisis: The importance of hedging. Finance and Economics Discussion Series, Federal Reserve Board of Governors 2012-27.

[10] Campello, M., E. Giambona, J. R. Graham, and C. R. Harvey. 2011. Liquidity Management and Corporate Investment during the Financial Crisis. Review of Financial Studies, 24(6), 1944-1979.

[11] Cornett, M.M., J.J. McNutt, P.E. Strahan, and H. Tehranian. 2011. Liquidity risk management and credit supply in the financial crisis. Journal of Financial Economics, 101, 297-312.

[12] De Nicolo, G., A. Gamba, and M. Lucchetta. 2014. Microprudential Regulation in a Dynamic Model of Banking. Review of Financial Studies, 27(7), 2098-2138.

[13] Diamond, W.D. and P.H. Dybvig. 1983. Bank Runs, Deposit Insurance and Liquidity. Journal of Political Economy, 91(3), 401-419.

[14] Flannery, J. M., S.H. Kwan, and M. Nimalendran. 2004. Market Evidence on the Opaqueness of Banking Firms' Assets. Journal of Financial Economics, 71(3), 419-460.

[15] Flannery, J. M., S.H. Kwan, and M. Nimalendran. 2010. The 2007-09 Financial Crisis and Bank Opaqueness. Federal Reserve Bank of San Francisco Working Paper Series, 27.

[16] Gatev, E., and P. E. Strahan. 2006. Banks' Advantage in Hedging Liquidity Risk: Theory and Evidence from the Commercial Paper Market. Journal of Finance, 61, 867-92. 
[17] Gatev, E., T. Schuermann, and P. E. Strahan. 2009. Managing Bank Liquidity Risk: How Deposit-Loan Synergies Vary with Market Conditions. Review of Financial Studies, 22, 995-1020.

[18] Gatev, E., T. Schuermann, and P. E. Strahan. 2006. How do Banks Manage Liquidity Risk? Evidence from the Equity and Deposit Markets in the Fall of 1998, in M. Carey and R. Stulz (eds.), Risks of Financial Institutions. Chicago, IL: University of Chicago Press, 105-27.

[19] Gersbach, H. and J-C Rochet. 2012. Aggregate Investment Externalities and Macroprudential Regulation. Journal of Money, Credit and Banking, 44, 73-109.

[20] Hadar, J., Russell, W.R.,. 1969. Rules for ordering uncertain prospects. American Economic Review, 59, 25-34.

[21] Holod, D., and J. Peek. 2010. Capital Constraints, Asymmetric Information, and Internal Capital Markets in Banking: New Evidence. Journal of Money, Credit and Banking, $42(5), 879-906$.

[22] Ivashina, V. and D. S. Scharfstein. 2010. Bank Lending during the Financial Crisis of 2008. Journal of Financial Economics, 97(3), 319-338.

[23] Kashyap, A.K., R.G. Rajan, and J.C. Stein. 2002. Banks as Liquidity Providers: An Explanation for the Co-Existence of Lending and Deposit-Taking. Journal of Finance, $57,33-74$.

[24] Kashyap, A.K., and J.C. Stein. 2000. What Do a Million Observations on Banks Say About the Transmission of Monetary Policy?. American Economic Review, 90(3), 407428.

[25] Kuosmanen, T. 2004. Efficient Diversification According to Stochastic Dominance Criteria. Management Science, 50, 1390-406. 
[26] Mankart, J., A. Michaelides, and S. Pagratis. 2015. Bank Capital Buffers in a Dynamic Model. available at SSRN: https://ssrn.com/abstract=2532875.

[27] Papanikolaou, N. I and C. C. P Wolff. 2014. The role of on- and off-balance-sheet leverage of banks in the late 2000s crisis. Journal of Financial Stability, 14, 3-22.

[28] Post, T. 2003. Empirical Tests for Stochastic Dominance Efficiency. Journal of Finance, 58, 1905-2031.

[29] Rio, E. 2000. Théorie asymptotique des processus aléatoires faiblement dépendants. Mathématiques et Applications, 31. Springer-Verlag, Berlin.

[30] Rochet, J-C, and X. Vives. 2004. Coordination Failures and the Lender of Last Resort: Was Bagehot Right After All?. Journal of the European Economic Association, 2(6), $1116-1147$.

[31] Scaillet, O., and N. Topaloglou. 2010. Testing for stochastic dominance efficiency. Journal of Business and Economic Statistics, 28(1), 169-80. 
TABLE 1 - AVERAGE CONSOLIDATED BALANCE SHEET OF U.S. BANK HOLDING COMPANIES, FOR 2007:Q3-2008:Q2

\begin{tabular}{|c|c|c|c|c|c|c|c|c|}
\hline \multirow[b]{2}{*}{ BALANCE SHEET COMPOSITION } & \multicolumn{4}{|c|}{ PANEL A: SMALL BANKS } & \multicolumn{4}{|c|}{ PANEL B: LARGE BANKS } \\
\hline & 2007:Q3 & 2007:Q4 & 2008:Q1 & 2008:Q2 & 2007:Q3 & 2007:Q4 & 2008:Q1 & 2008:Q2 \\
\hline Number of banks & 105 & 106 & 115 & 120 & 63 & 65 & 67 & 61 \\
\hline Mean tangible assets (2008 \$millions) & 616 & 650 & 669 & 684 & 6812 & 6895 & 6373 & 6327 \\
\hline Median tangible assets (2008 \$millions) & 548 & 585 & 589 & 615 & 3303 & 3769 & 3722 & 3422 \\
\hline \multicolumn{9}{|l|}{ Asset classes } \\
\hline \multicolumn{9}{|l|}{ Proportion of tangible total assets } \\
\hline 1. Cash, Fed funds sold \& Reverse Repo & 0.04 & 0.04 & 0.05 & 0.04 & 0.04 & 0.04 & 0.04 & 0.04 \\
\hline 2. Loans secured by real estate & 0.52 & 0.52 & 0.52 & 0.52 & 0.52 & 0.51 & 0.53 & 0.54 \\
\hline 3. Commercial \& Industrial loans & 0.09 & 0.09 & 0.10 & 0.10 & 0.11 & 0.11 & 0.11 & 0.11 \\
\hline 4. Loans to individuals & 0.03 & 0.03 & 0.03 & 0.03 & 0.04 & 0.05 & 0.04 & 0.05 \\
\hline 5. Other loans & 0.04 & 0.03 & 0.03 & 0.04 & 0.03 & 0.03 & 0.03 & 0.03 \\
\hline 6. Government securities & 0.11 & 0.10 & 0.09 & 0.09 & 0.06 & 0.06 & 0.06 & 0.05 \\
\hline 7. Agency MBS & 0.09 & 0.09 & 0.09 & 0.10 & 0.10 & 0.10 & 0.09 & 0.10 \\
\hline 8. Equities & 0.01 & 0.01 & 0.01 & 0.01 & 0.00 & 0.00 & 0.00 & 0.00 \\
\hline 9. Other securities & 0.02 & 0.02 & 0.02 & 0.02 & 0.02 & 0.02 & 0.02 & 0.02 \\
\hline 10. Other tangible assets & 0.06 & 0.05 & 0.05 & 0.05 & 0.07 & 0.08 & 0.07 & 0.07 \\
\hline \multicolumn{9}{|l|}{ Liability classes } \\
\hline \multicolumn{9}{|l|}{ Proportion of total liabilities } \\
\hline 1. Fed funds purchased \& Repo & 0.04 & 0.04 & 0.04 & 0.04 & 0.06 & 0.06 & 0.06 & 0.06 \\
\hline 2. Demand deposits & 0.07 & 0.07 & 0.07 & 0.07 & 0.06 & 0.06 & 0.06 & 0.06 \\
\hline 3. Interest bearing transaction deposits & 0.05 & 0.05 & 0.05 & 0.05 & 0.02 & 0.03 & 0.03 & 0.03 \\
\hline 4. Time deposits less than $\$ 100,000$ & 0.25 & 0.24 & 0.24 & 0.23 & 0.18 & 0.18 & 0.18 & 0.18 \\
\hline 5. Time deposits more than $\$ 100,000$ & 0.13 & 0.13 & 0.13 & 0.13 & 0.13 & 0.13 & 0.13 & 0.12 \\
\hline 6. Other deposits & 0.28 & 0.28 & 0.28 & 0.28 & 0.39 & 0.37 & 0.37 & 0.36 \\
\hline 7. Other liabilities & 0.09 & 0.09 & 0.10 & 0.10 & 0.08 & 0.09 & 0.09 & 0.11 \\
\hline Tangible equity & 0.09 & 0.09 & 0.09 & 0.09 & 0.08 & 0.08 & 0.08 & 0.08 \\
\hline
\end{tabular}

This table shows average balance sheets of small and large U.S. commercial banks, for the period 2007:Q3-2008:Q2. Bank size is defined relative to the $95^{\text {th }}$ percentile of the distribution of tangible total assets in each quarter. Average balance sheets are based on the sample used for the optimization procedure, and bank size is defined on the basis of the whole sample, as we discuss in Section 4. 
TABLE 2 - LINEAR CORRELATIONS AND BASIC MOMENTS OF THE UNSTRUCTURED COMPONENT OF GROWTH RATES IN ASSETS AND LIABILITIES OF LARGE U.S. BANK HOLDING COMPANIES, FOR 2008:Q1

\begin{tabular}{|c|c|c|c|c|c|c|c|c|c|c|c|c|c|c|c|c|c|}
\hline \multirow{2}{*}{$\begin{array}{l}\text { DESCRIPTIVE STATISTICS } \\
\text { OF GROWTH RATES } \\
\end{array}$} & \multicolumn{10}{|c|}{ Correlation with asset classes } & \multicolumn{7}{|c|}{ Correlation with liability classes } \\
\hline & 1 & 2 & 3 & 4 & 5 & 6 & 7 & 8 & 9 & 10 & 1 & 2 & 3 & 4 & 5 & 6 & 7 \\
\hline Asset classes & & & & & & & & & & & & & & & & & \\
\hline 1. Cash, Fed funds \& Repo & 1.00 & & & & & & & & & & & & & & & & \\
\hline 2. Real estate loans & 0.15 & 1.00 & & & & & & & & & & & & & & & \\
\hline 3. C\&I loans & 0.04 & 0.26 & 1.00 & & & & & & & & & & & & & & \\
\hline 4. Loans to individuals & -0.12 & 0.37 & 0.00 & 1.00 & & & & & & & & & & & & & \\
\hline 5. Other loans & 0.14 & 0.48 & 0.33 & 0.15 & 1.00 & & & & & & & & & & & & \\
\hline 6. Government securities & -0.07 & 0.17 & 0.18 & 0.04 & 0.22 & 1.00 & & & & & & & & & & & \\
\hline 7. Agency MBS & -0.10 & 0.19 & 0.11 & -0.11 & -0.04 & -0.17 & 1.00 & & & & & & & & & & \\
\hline 8. Equities & 0.05 & 0.06 & -0.02 & 0.07 & -0.08 & 0.14 & -0.18 & 1.00 & & & & & & & & & \\
\hline 9. Other securities & -0.08 & 0.14 & 0.00 & 0.22 & 0.17 & 0.25 & -0.05 & 0.29 & 1.00 & & & & & & & & \\
\hline 10. Other tangible assets & 0.12 & 0.23 & 0.09 & 0.05 & 0.03 & -0.10 & 0.26 & -0.11 & -0.06 & 1.00 & & & & & & & \\
\hline Liability classes & & & & & & & & & & & & & & & & & \\
\hline 1. Fed funds \& Repo & 0.14 & 0.22 & 0.00 & -0.10 & 0.06 & -0.14 & 0.01 & -0.03 & 0.13 & 0.11 & 1.00 & & & & & & \\
\hline 2. Demand deposits & 0.10 & -0.12 & -0.17 & 0.03 & 0.06 & 0.00 & -0.15 & 0.20 & 0.15 & -0.07 & -0.11 & 1.00 & & & & & \\
\hline 3. Interest bearing trans.deposits & -0.08 & 0.15 & 0.19 & 0.21 & 0.08 & 0.28 & 0.10 & 0.07 & -0.01 & -0.10 & -0.43 & 0.13 & 1.00 & & & & \\
\hline 4. Time deposits $\leq \$ 100,000$ & -0.23 & 0.27 & 0.03 & 0.34 & 0.09 & 0.27 & -0.01 & 0.02 & -0.01 & 0.15 & -0.15 & -0.07 & 0.16 & 1.00 & & & \\
\hline 5. Time deposits $>\$ 100,000$ & 0.07 & -0.10 & 0.01 & 0.16 & -0.25 & 0.00 & 0.07 & 0.10 & 0.04 & -0.08 & -0.17 & -0.03 & 0.04 & -0.11 & 1.00 & & \\
\hline 6. Other deposits & 0.05 & 0.34 & 0.15 & 0.20 & 0.05 & 0.12 & 0.08 & 0.00 & -0.06 & 0.31 & 0.04 & -0.36 & 0.05 & -0.06 & -0.08 & 1.00 & \\
\hline 7. Other liabilities & -0.06 & 0.16 & 0.08 & 0.03 & 0.18 & -0.33 & 0.09 & -0.25 & -0.19 & 0.07 & -0.01 & -0.25 & -0.13 & 0.10 & -0.17 & 0.01 & 1.00 \\
\hline Mean & -0.04 & -0.01 & 0.00 & 0.01 & 0.01 & -0.12 & 0.03 & 0.10 & 0.00 & 0.01 & 0.02 & 0.00 & -0.04 & -0.01 & -0.04 & 0.00 & 0.10 \\
\hline Standard deviation & 0.28 & 0.04 & 0.09 & 0.08 & 0.19 & 0.22 & 0.15 & 0.87 & 0.29 & 0.11 & 0.40 & 0.19 & 0.26 & 0.13 & 0.09 & 0.10 & 0.29 \\
\hline Skewness & 0.24 & 3.83 & -0.31 & 0.93 & 1.13 & -1.49 & 0.29 & 2.68 & 0.35 & 1.74 & 0.56 & -1.80 & -0.14 & 3.01 & -0.59 & 3.07 & 1.04 \\
\hline Kurtosis & 5.26 & 24.93 & 5.62 & 6.22 & 10.47 & 8.45 & 3.58 & 14.66 & 4.84 & 7.21 & 7.48 & 11.04 & 8.10 & 18.37 & 3.70 & 15.89 & 5.18 \\
\hline Obs. & 67 & 67 & 67 & 67 & 67 & 67 & 67 & 67 & 67 & 67 & 67 & 67 & 67 & 67 & 67 & 67 & 67 \\
\hline
\end{tabular}

This table shows linear correlations and the first four moments of unstructured growth rates in assets and liabilities for large banks in 2008:Q1. The unstructured components of growth rates are the same used in the optimization procedure for quarter 2008:Q1. They are obtained from growth rates in balance sheet classes by filtering out seasonalities, individual bank fixed effects, and autocorrelation, as we discuss in Section 4. 
TABLE 3 - AVERAGE GROWTH RATE IN THE RATIO OF FAIR VALUE TO AMORTIZED COST OF LIQUID SECURITIES HOLDINGS OF U.S. BANK HOLDING COMPANIES, FOR THE PERIOD 2007:Q1-2009:Q1

\begin{tabular}{|c|c|c|c|c|c|c|c|c|c|c|}
\hline & \multicolumn{2}{|c|}{$\begin{array}{c}\text { Number of } \\
\text { observations }\end{array}$} & \multicolumn{2}{|c|}{ Government } & \multicolumn{2}{|c|}{ Agency MBS } & \multicolumn{2}{|c|}{ Equities } & \multicolumn{2}{|c|}{ Other AFS securities } \\
\hline & Small & Large & Small & Large & Small & Large & Small & Large & Small & Large \\
\hline 2007:Q1 & 345 & 84 & $0.17 \%$ & $0.15 \%$ & $0.37 \%$ & $0.42 \%$ & $0.05 \%$ & $0.26 \%$ & $0.30 \%$ & $0.17 \%$ \\
\hline 2007:Q2 & 351 & 83 & $-1.05 \%$ & $-0.80 \%$ & $-1.17 \%$ & $-1.25 \%$ & $0.03 \%$ & $-0.69 \%$ & $-0.68 \%$ & $-0.67 \%$ \\
\hline 2007:Q3 & 349 & 78 & $1.14 \%$ & $0.97 \%$ & $1.20 \%$ & $1.24 \%$ & $-1.33 \%$ & $1.95 \%$ & $-0.19 \%$ & $-0.49 \%$ \\
\hline 2007:Q4 & 340 & 75 & $0.71 \%$ & $0.74 \%$ & $1.03 \%$ & $1.01 \%$ & $-8.41 \%$ & $-2.54 \%$ & $-0.69 \%$ & $-1.59 \%$ \\
\hline 2008:Q1 & 358 & 80 & $0.84 \%$ & $0.91 \%$ & $1.17 \%$ & $1.24 \%$ & $-5.06 \%$ & $2.56 \%$ & $-2.22 \%$ & $-2.32 \%$ \\
\hline 2008:Q2 & 392 & 76 & $-1.63 \%$ & $-1.39 \%$ & $-1.99 \%$ & $-1.80 \%$ & $-1.89 \%$ & $-0.72 \%$ & $-3.14 \%$ & $-3.07 \%$ \\
\hline 2008:Q3 & 400 & 83 & $-0.86 \%$ & $-0.91 \%$ & $0.86 \%$ & $0.59 \%$ & $-7.18 \%$ & $-8.36 \%$ & $-8.69 \%$ & $-10.34 \%$ \\
\hline 2008:Q4 & 370 & 87 & $1.45 \%$ & $1.44 \%$ & $1.61 \%$ & $1.61 \%$ & $-18.33 \%$ & $-3.90 \%$ & $-1.53 \%$ & $-3.38 \%$ \\
\hline 2009:Q1 & 378 & 87 & $0.16 \%$ & $0.09 \%$ & $0.70 \%$ & $0.78 \%$ & $-0.30 \%$ & $-1.75 \%$ & $-6.68 \%$ & $-6.24 \%$ \\
\hline
\end{tabular}

This table shows average quarterly growth rate in the ratio of fair-value to amortized cost of liquid securities holdings of small and large U.S. commercial banks during the 2007-09 crisis. Growth rates measure changes in fair value, where the denominator (amortized cost) controls for changes in stock. Since 2007:Q4 equities and other AFS securities show average fair value losses that in certain instances are several times higher than fair value losses in government securities and agency MBS. Therefore, equities and other AFS securities are excluded from HQLA, including only cash, Fed funds sold and repo, government securities, and agency MBS. 
TABLE 4 - CROSS SECTIONAL REGRESSIONS FOR MAPPING BALANCE SHEET WEIGHTS INTO PROFITABILITY OF U.S. BANK HOLDING COMPANIES, FOR THE PERIOD 2002:Q1-2009:Q1

\begin{tabular}{|c|c|c|c|c|c|c|}
\hline \multirow{2}{*}{$\begin{array}{l}\text { DEPENDENT VARIABLE: } \\
\text { logarithm of net interest margin } \\
\text { INDEPENDENT VARIABLES: } \\
\text { Loan and liquid asset classes } \\
\text { fraction of tangible assets } \times \\
\text { growth in stock }\end{array}$} & \multicolumn{2}{|c|}{ Coefficient } & \multicolumn{2}{|c|}{$\begin{array}{l}\text { Bootstrap } \\
\text { Std. Errors }\end{array}$} & \multicolumn{2}{|c|}{$\begin{array}{l}\text { Coefficient } \times \\
\text { Mean Growth Rate }\end{array}$} \\
\hline & Small & Large & Small & Large & Small & Large \\
\hline 1. Cash, Fed funds sold \& Reverse Repo & -0.203 & $-0.555^{* *}$ & 0.293 & 0.265 & -0.207 & -0.572 \\
\hline 2. Real estate loans & $0.632^{* * *}$ & $0.485^{* *}$ & 0.096 & 0.208 & 0.647 & 0.497 \\
\hline 3. Commercial \& Industrial loans & $0.695^{* * *}$ & $0.533^{* *}$ & 0.162 & 0.235 & 0.704 & 0.540 \\
\hline 4. Loans to individuals & $1.168^{* * *}$ & $1.186^{* * *}$ & 0.226 & 0.317 & 1.148 & 1.176 \\
\hline 5. Other loans & $1.005^{* * *}$ & $0.707^{*}$ & 0.156 & 0.435 & 1.003 & 0.726 \\
\hline \multicolumn{7}{|l|}{ Available for sale securities } \\
\hline 6. Government securities & $0.286^{* * *}$ & 0.021 & 0.110 & 0.243 & 0.286 & 0.021 \\
\hline 7. Agency MBS & - & - & - & - & 0.000 & 0.000 \\
\hline 8. Equities & 0.368 & -0.875 & 0.579 & 1.461 & 0.355 & -0.835 \\
\hline 9. Other available-for-sale securities & -0.614 & -0.049 & 0.454 & 0.460 & -0.590 & -0.047 \\
\hline 10. Other tangible assets & 0.097 & 0.107 & 0.171 & 0.221 & 0.099 & 0.110 \\
\hline \multicolumn{7}{|l|}{$\begin{array}{l}\text { Liquid liability classes } \\
\text { fraction of total liabilities } \times \\
\text { growth in stock }\end{array}$} \\
\hline 1. Fed funds purchased \& Repo & $-1.170^{* * *}$ & $-0.592^{* * *}$ & 0.227 & 0.188 & -1.075 & $-\mathbf{0 . 5 3 0}$ \\
\hline 2. Demand deposits & $0.526^{* * *}$ & 0.088 & 0.178 & 0.240 & 0.482 & 0.082 \\
\hline 3. Interest bearing transaction deposits & -0.028 & 0.207 & 0.158 & 0.282 & -0.025 & 0.195 \\
\hline 4. Time deposits less than $\$ 100,000$ & $-0.817^{* * *}$ & $-0.994^{* * *}$ & 0.124 & 0.173 & -0.757 & -0.927 \\
\hline 5. Time deposits more than $\$ 100,000$ & $-0.646^{* * *}$ & -0.183 & 0.144 & 0.254 & -0.604 & -0.172 \\
\hline 6. Other deposits & - & - & - & - & 0.000 & 0.000 \\
\hline $\begin{array}{l}\text { 7. Other liabilities } \\
\text { Other variables }\end{array}$ & $-1.160^{* * *}$ & $-0.573^{* * *}$ & 0.165 & 0.203 & -1.076 & -0.536 \\
\hline Constant & $-4.856^{* * *}$ & $-4.787^{* * *}$ & 0.100 & 0.187 & & \\
\hline \multicolumn{5}{|c|}{ Profitability target (mean logarithm of net interest margin minus constant) } & 0.099 & 0.069 \\
\hline \multicolumn{7}{|c|}{\begin{tabular}{ll}
\multirow{2}{*}{ Small banks } & $\mathrm{R}^{2}: 55 \% ; \quad$ Adjusted $\mathrm{R}^{2}: 54 \%$ \\
& Wald chi2 (11): 288; Number of banks: 277 \\
\end{tabular}} \\
\hline \multicolumn{7}{|c|}{\begin{tabular}{ll}
\multirow{2}{*}{ Large banks } & $\mathrm{R}^{2}: 42 \% ; \quad$ Adjusted $\mathrm{R}^{2}: 38 \%$ \\
& Wald chi2 (15): $97 ;$ Number of banks: 206
\end{tabular}} \\
\hline
\end{tabular}

This table shows estimated coefficients of reduced-form models for net interest margin (i.e. the ratio of net interest income to interest earning assets), by bank size. Multiplying the coefficients by the respective mean growth rate in asset and liability classes we obtain loadings for the profitability constraint to the optimization problem. These are shown in the last two columns in bold, with profitability targets shown at the bottom. Bootstrap standard errors on 300 replications are reported in the thirds column. Statistical significance at $1 \%, 5 \%$ and $10 \%$ level is denoted by $* * *, * *$ and * respectively. 
TABLE 5 - CROSS SECTIONAL REGRESSIONS FOR MAPPING BALANCE SHEET WEIGHTS INTO TIER 1 CAPITAL RATIO OF U.S. BANK HOLDING COMPANIES, FOR THE PERIOD 2002:Q1-2009:Q1

\begin{tabular}{|c|c|c|c|c|c|c|}
\hline \multirow{2}{*}{$\begin{array}{l}\text { DEPENDENT VARIABLE: logarithm of } \\
\text { Tier } 1 \text { capital ratio (Tierl-ratio }{ }_{\text {it }} \text { ) } \\
\text { INDEPENDENT VARIABLES: } \\
\text { Loan and liquid asset classes } \\
\text { fraction of tangible assets } \times \\
\text { growth rate in stock }\end{array}$} & \multicolumn{2}{|c|}{ Coefficient } & \multicolumn{2}{|c|}{$\begin{array}{l}\text { Bootstrap } \\
\text { Std. Errors }\end{array}$} & \multicolumn{2}{|c|}{$\begin{array}{l}\text { Coefficient } \times \\
\text { Mean Growth Rate }\end{array}$} \\
\hline & Small & Large & Small & Large & Small & Large \\
\hline 1. Cash, Fed funds sold \& Reverse Repo & 0.561 & 0.016 & 0.594 & 0.299 & 0.573 & 0.016 \\
\hline 2. Real estate loans & $-0.591^{* * *}$ & $-0.821^{* * *}$ & 0.156 & 0.145 & -0.605 & -0.842 \\
\hline 3. Commercial \& Industrial loans & $-1.053^{* * *}$ & $-1.083^{* * *}$ & 0.228 & 0.242 & -1.067 & -1.097 \\
\hline 4. Loans to individuals & 0.082 & $-0.706^{* *}$ & 0.424 & 0.328 & 0.080 & -0.700 \\
\hline 5. Other loans & $-0.792^{* * *}$ & $-1.561^{* * *}$ & 0.265 & 0.447 & -0.791 & -1.603 \\
\hline \multicolumn{7}{|l|}{ Available for sale securities } \\
\hline 6. Government securities & $0.424^{* *}$ & 0.136 & 0.217 & 0.255 & 0.423 & 0.135 \\
\hline 7. Agency MBS & & & & & 0.000 & 0.000 \\
\hline 8. Equities & -0.449 & 0.870 & 0.841 & 1.416 & -0.433 & 0.830 \\
\hline 9. Other available-for-sale securities & $-0.972^{* *}$ & -0.116 & 0.460 & 0.516 & -0.935 & -0.110 \\
\hline 10. Other tangible assets & 0.387 & 0.166 & 0.429 & 0.385 & 0.395 & 0.170 \\
\hline \multicolumn{7}{|l|}{$\begin{array}{l}\text { Liquid liability classes } \\
\text { fraction of total liabilities } \times \\
\text { growth in stock }\end{array}$} \\
\hline 1. Fed funds purchased \& Repo & -0.373 & -0.082 & 0.340 & 0.214 & -0.343 & -0.074 \\
\hline 2. Demand deposits & -0.162 & -0.086 & 0.279 & 0.247 & -0.148 & -0.080 \\
\hline 3. Interest bearing transaction deposits & 0.237 & 0.127 & 0.300 & 0.355 & 0.215 & 0.120 \\
\hline 4. Time deposits less than $\$ 100,000$ & 0.141 & $0.293^{*}$ & 0.169 & 0.166 & 0.131 & 0.273 \\
\hline 5. Time deposits more than $\$ 100,000$ & $-0.489^{* *}$ & $-0.277^{* *}$ & 0.203 & 0.143 & -0.457 & -0.261 \\
\hline 6. Other deposits & & & & & 0.000 & 0.000 \\
\hline 7. Other liabilities & 0.069 & 0.091 & 0.204 & 0.220 & 0.064 & 0.085 \\
\hline \multicolumn{7}{|l|}{ Other variables } \\
\hline Constant & $-1.733^{* * *}$ & $-1.688^{* * *}$ & 0.159 & 0.149 & & \\
\hline \multicolumn{5}{|c|}{ Tier 1 capital target (mean logarithm of Tier 1 ratio minus constant) } & -0.385 & -0.561 \\
\hline \multicolumn{7}{|c|}{\begin{tabular}{ll}
\multirow{2}{*}{ Small banks } & $\mathrm{R}^{2}: 35 \%$ Adjusted $\mathrm{R}^{2}: 31 \%$ \\
& Wald chi2 (15): $124 ;$ Number of banks: 277 \\
\end{tabular}} \\
\hline \multicolumn{7}{|l|}{ Large banks } \\
\hline
\end{tabular}

This table shows estimated coefficients of reduced-form models for Tier-1 capital ratio, by bank size. Multiplying the coefficients by the respective mean growth rate in asset and liability classes we obtain loadings for the capital adequacy constraint to the optimization problem. These are shown in the last two columns in bold, with capital adequacy targets shown at the bottom. Bootstrap standard errors on 300 replications are reported in the thirds column. Statistical significance at $1 \%, 5 \%$ and $10 \%$ level is denoted by $* * *, * *$ and $*$ respectively. 
TABLE 6 - SDE BALANCE SHEETS OF U.S. BANK HOLDING COMPANIES, FOR THE STRESS PERIOD 2007:Q3-2008:Q2

\begin{tabular}{|c|c|c|c|c|c|c|c|c|}
\hline \multirow[b]{2}{*}{ SDE BALANCE SHEETS } & \multicolumn{4}{|c|}{ PANEL A: SMALL BANKS } & \multicolumn{4}{|c|}{ PANEL B: LARGE BANKS } \\
\hline & 2007:Q3 & 2007:Q4 & 2008:Q1 & 2008:Q2 & 2007:Q3 & 2007:Q4 & 2008:Q1 & 2008:Q2 \\
\hline Number of banks & 105 & 106 & 115 & 120 & 63 & 65 & 67 & 61 \\
\hline Mean tangible assets (2008 \$millions) & 616 & 650 & 669 & 684 & 6812 & 6895 & 6373 & 6327 \\
\hline Median tangible assets (2008 \$millions) & 548 & 585 & 589 & 615 & 3303 & 3769 & 3722 & 3422 \\
\hline \multicolumn{9}{|l|}{ Asset classes } \\
\hline \multicolumn{9}{|l|}{ Proportion of tangible total assets } \\
\hline 1. Cash, Fed funds sold \& Reverse Repo & 0.05 & 0.05 & 0.00 & 0.00 & 0.14 & 0.00 & 0.00 & 0.13 \\
\hline 2. Loans secured by real estate & 0.48 & 0.48 & 0.52 & 0.48 & 0.47 & 0.47 & 0.47 & 0.47 \\
\hline 3. Commercial \& Industrial loans & 0.10 & 0.10 & 0.10 & 0.10 & 0.11 & 0.11 & 0.11 & 0.11 \\
\hline 4. Loans to individuals & 0.05 & 0.04 & 0.19 & 0.28 & 0.06 & 0.08 & 0.06 & 0.06 \\
\hline 5. Other loans & 0.04 & 0.04 & 0.05 & 0.06 & 0.03 & 0.03 & 0.03 & 0.03 \\
\hline 6. Government securities & 0.15 & 0.29 & 0.14 & 0.09 & 0.11 & 0.28 & 0.34 & 0.08 \\
\hline 7. Agency MBS & 0.00 & 0.00 & 0.00 & 0.00 & 0.00 & 0.00 & 0.00 & 0.02 \\
\hline 8. Equities & 0.00 & 0.00 & 0.00 & 0.00 & 0.00 & 0.04 & 0.00 & 0.11 \\
\hline 9. Other securities & 0.01 & 0.00 & 0.00 & 0.00 & 0.00 & 0.00 & 0.00 & 0.00 \\
\hline 10. Other tangible assets & 0.13 & 0.00 & 0.02 & 0.00 & 0.09 & 0.00 & 0.00 & 0.00 \\
\hline \multicolumn{9}{|l|}{ Liability classes } \\
\hline \multicolumn{9}{|l|}{ Proportion of total liabilities } \\
\hline 1. Fed funds purchased \& Repo & 0.20 & 0.19 & 0.15 & 0.13 & 0.16 & 0.00 & 0.08 & 0.00 \\
\hline 2. Demand deposits & 0.00 & 0.00 & 0.01 & 0.02 & 0.00 & 0.17 & 0.18 & 0.56 \\
\hline 3. Interest bearing transaction deposits & 0.00 & 0.19 & 0.06 & 0.32 & 0.00 & 0.14 & 0.05 & 0.27 \\
\hline 4. Time deposits less than $\$ 100,000$ & 0.00 & 0.29 & 0.00 & 0.00 & 0.10 & 0.12 & 0.07 & 0.12 \\
\hline 5. Time deposits more than $\$ 100,000$ & 0.00 & 0.00 & 0.00 & 0.05 & 0.00 & 0.00 & 0.00 & 0.03 \\
\hline 6. Other deposits & 0.74 & 0.31 & 0.37 & 0.00 & 0.64 & 0.17 & 0.35 & 0.00 \\
\hline 7. Other liabilities & 0.06 & 0.02 & 0.42 & 0.48 & 0.11 & 0.40 & 0.27 & 0.02 \\
\hline
\end{tabular}

This table shows SDE optimization results conditionally on the largest liquidity shocks to the U.S. commercial banking system, for large and small banks. SDE weights provide a measure of liquidity contributions of balance sheet classes. Liquid asset classes are assigned a high (low) SDE weight if monetization of assets from these classes tends to offset a large (small) proportion of liquidity demands from assets and liabilities. Liability classes receive a high (low) SDE weight if funding inflows (outflows) in these classes tend to mitigate (exacerbate) cash outflows from other balance sheet classes. 
TABLE 7 - SDE BALANCE SHEETS OF U.S. BANK HOLDING COMPANIES UNDER ALTERNATIVE OPTIMIZATION CONSTRAINTS, CONDITIONALLY ON 2007:Q4 AND 2008:Q1 STRESS SCENARIOS

\begin{tabular}{|c|c|c|c|c|c|c|c|c|}
\hline \multirow[b]{2}{*}{ SDE BALANCE SHEETS } & \multicolumn{4}{|c|}{$\begin{array}{c}\text { PANEL A: SMALL BANKS } \\
\text { CONDITIONALLY ON 2007:Q4 }\end{array}$} & \multicolumn{4}{|c|}{$\begin{array}{c}\text { PANEL B: LARGE BANKS } \\
\text { CONDITIONALLY ON 2008:Q1 }\end{array}$} \\
\hline & $\begin{array}{l}\text { Only loan } \\
\text { constraints }\end{array}$ & $\begin{array}{l}\text { Capital \&loan } \\
\text { constraints }\end{array}$ & $\begin{array}{l}\text { Profit \&loan } \\
\text { constraints }\end{array}$ & $\begin{array}{l}\text { All } \\
\text { constraints }\end{array}$ & $\begin{array}{l}\text { Only loan } \\
\text { constraints }\end{array}$ & $\begin{array}{l}\text { Capital \&loan } \\
\text { constraints }\end{array}$ & $\begin{array}{l}\text { Profit \&loan } \\
\text { constraints }\end{array}$ & $\begin{array}{l}\text { All } \\
\text { constraints }\end{array}$ \\
\hline \multicolumn{9}{|l|}{ Asset classes } \\
\hline \multicolumn{9}{|l|}{ Proportion of tangible total assets } \\
\hline 1. Cash, Fed funds sold \& Reverse Repo & 0.06 & 0.09 & 0.06 & 0.05 & 0.00 & 0.00 & 0.03 & 0.00 \\
\hline 2. Loans secured by real estate & 0.48 & 0.48 & 0.49 & 0.48 & 0.47 & 0.47 & 0.47 & 0.47 \\
\hline 3. Commercial \& Industrial loans & 0.10 & 0.10 & 0.10 & 0.10 & 0.11 & 0.11 & 0.11 & 0.11 \\
\hline 4. Loans to individuals & 0.04 & 0.04 & 0.04 & 0.04 & 0.06 & 0.06 & 0.06 & 0.06 \\
\hline 5. Other loans & 0.04 & 0.04 & 0.04 & 0.04 & 0.03 & 0.03 & 0.03 & 0.03 \\
\hline 6. Government securities & 0.28 & 0.25 & 0.26 & 0.29 & 0.34 & 0.33 & 0.31 & 0.34 \\
\hline 7. Agency MBS & 0.00 & 0.00 & 0.01 & 0.00 & 0.00 & 0.00 & 0.00 & 0.00 \\
\hline 8. Equities & 0.00 & 0.00 & 0.00 & 0.00 & 0.00 & 0.00 & 0.00 & 0.00 \\
\hline 9. Other securities & 0.00 & 0.00 & 0.00 & 0.00 & 0.00 & 0.00 & 0.00 & 0.00 \\
\hline 10. Other tangible assets & 0.00 & 0.00 & 0.00 & 0.00 & 0.00 & 0.00 & 0.00 & 0.00 \\
\hline HQLA ratio & 0.34 & 0.34 & 0.33 & 0.34 & 0.34 & 0.34 & 0.34 & 0.34 \\
\hline \multicolumn{9}{|l|}{ Liability classes } \\
\hline \multicolumn{9}{|l|}{ Proportion of total liabilities } \\
\hline 1. Fed funds purchased \& Repo & 0.21 & 0.21 & 0.20 & 0.19 & 0.08 & 0.07 & 0.13 & 0.08 \\
\hline 2. Demand deposits & 0.00 & 0.00 & 0.00 & 0.00 & 0.18 & 0.19 & 0.04 & 0.18 \\
\hline 3. Interest bearing transaction deposits & 0.03 & 0.00 & 0.11 & 0.19 & 0.06 & 0.03 & 0.05 & 0.05 \\
\hline 4. Time deposits less than $\$ 100,000$ & 0.34 & 0.20 & 0.14 & 0.29 & 0.00 & 0.10 & 0.00 & 0.07 \\
\hline 5. Time deposits more than $\$ 100,000$ & 0.00 & 0.00 & 0.00 & 0.00 & 0.00 & 0.00 & 0.00 & 0.00 \\
\hline 6. Other deposits & 0.28 & 0.38 & 0.43 & 0.31 & 0.39 & 0.34 & 0.50 & 0.35 \\
\hline 7. Other liabilities & 0.14 & 0.21 & 0.13 & 0.02 & 0.28 & 0.29 & 0.29 & 0.27 \\
\hline
\end{tabular}

This table shows SDE balance sheets and HQLA ratios for U.S. commercial banks under alternative sets of constraints to the optimization problem and conditionally on 2007:Q4 and 2008:Q1 liquidity stress scenario for small and large, respectively. SDE weights provide a measure of liquidity contributions of balance sheet classes. Liquid asset classes are assigned a high (low) SDE weight if monetization of assets from these classes tends to offset a large (small) proportion of liquidity demands from assets and liabilities. Liability classes receive a high (low) SDE weight if funding inflows (outflows) in these classes tend to mitigate (exacerbate) cash outflows from other balance sheet classes. 


\section{FIGURE 1: SDE AND ACTUAL HQLA RATIOS OF U.S. BANK HOLDING COMPANIES, FOR THE PERIOD 2007:Q1-2009:Q1}

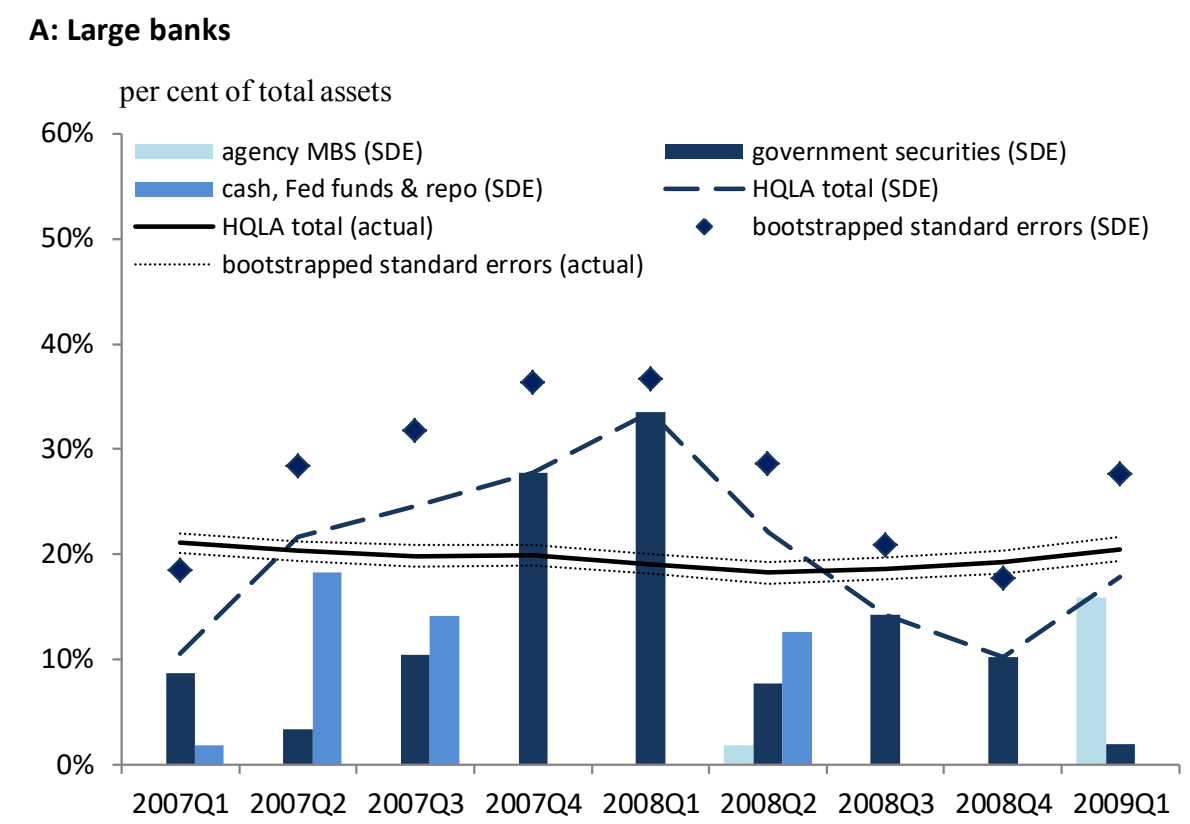

\section{B: Small banks}

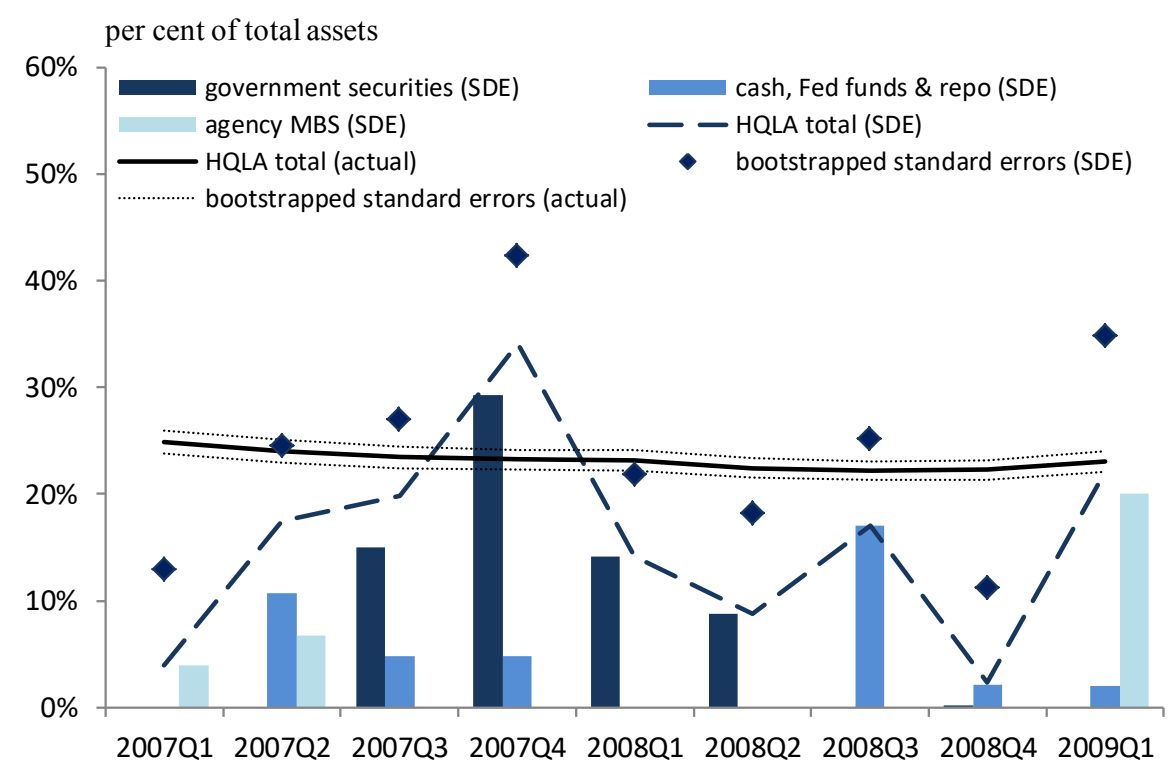

This figure shows average HQLA holdings (solid line) and estimated HQLA based on SDE balance sheets (dashed line) for large banks (Panel A) and small banks (Panel B), for the period 2007:Q12009:Q1. All quantities are expressed as a proportion of total assets. The aggregate liquidity shortfall corresponds to any shortfall of actual HQLA holdings relative to the SDE estimated. The decomposition of estimated SDE weights per HQLA class (cash, Fed funds sold and repo, government securities, and agency MBS) is shown each quarter in bars. Bank size (small, large) is defined relative to the 95th percentile of the distribution of total assets each quarter. Bootsrapped standard errors for actual (dotted lines) and estimated SDE ratios (diamonds) are based on 300 repetitions. 
FIGURE 2: BOOTSTRAPPED SDE WEIGHTS FOR HQLA, BY BANK SIZE

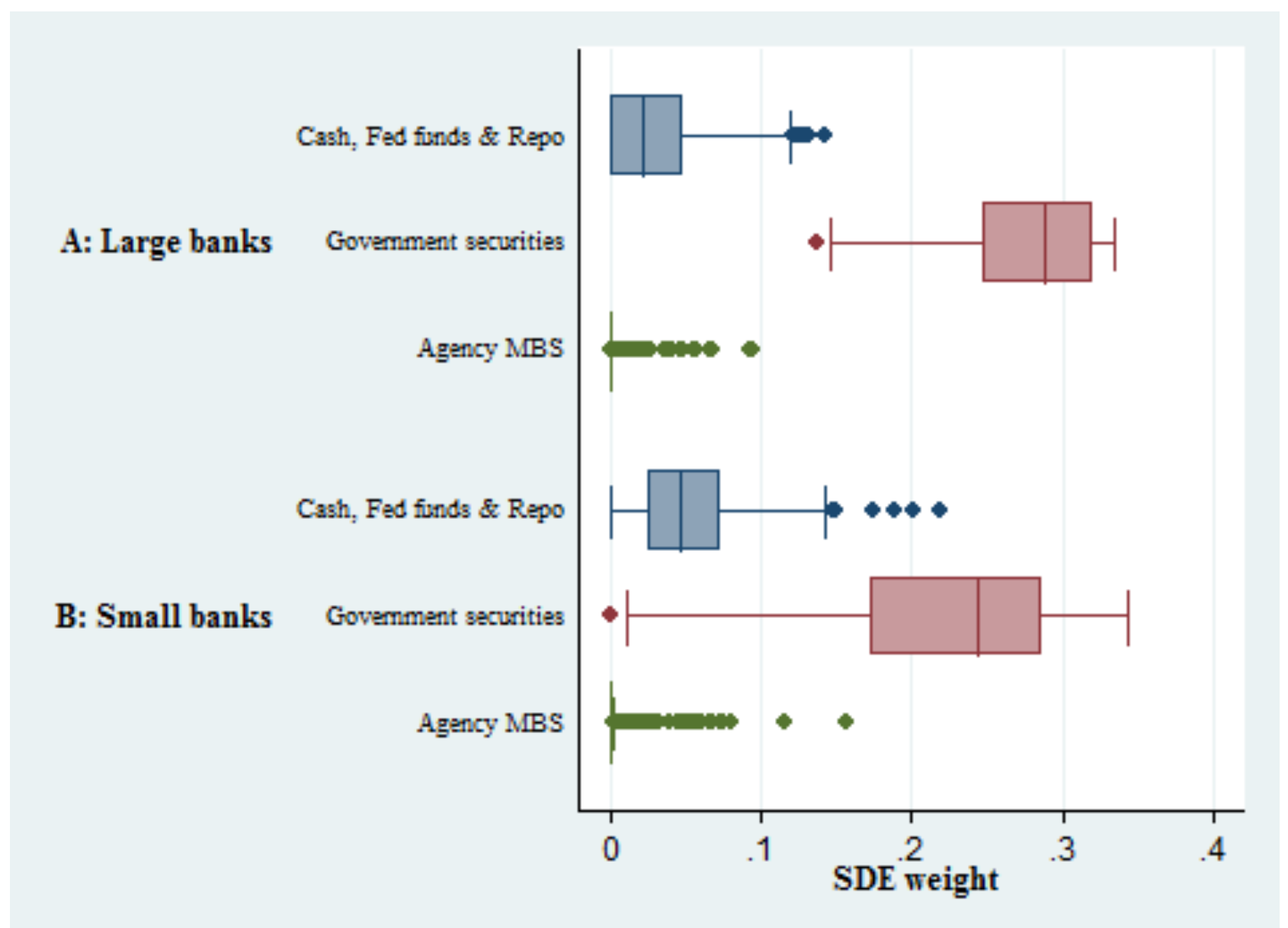

This figure shows the interquartile range of bootstrapped SDE weights for HQLA (outliers shown in dots), for large banks (Panel A) and small banks (Panel B) for the stress scenarios 2008:Q1 and 2007:Q4, respectively. The more advanced to the right the interquartile range for a given HQLA class, the more monetization of assets from this class tends to offset liquidity demands from asset and liabilities, and vice versa. The bootstrapping method draws random samples with replacement from the initial data, separately for small and large banks, maintaining the same sample size as the initial sample. For each bootstrap sample we solve the optimization problem and obtain SDE weights for asset and liability classes. We repeat this procedure 300 times and derive the distribution of SDE weights each quarter. 


\section{FIGURE 3: BOOTSTRAPPED SDE WEIGHTS FOR DEPOSIT CLASSES, BY BANK SIZE}

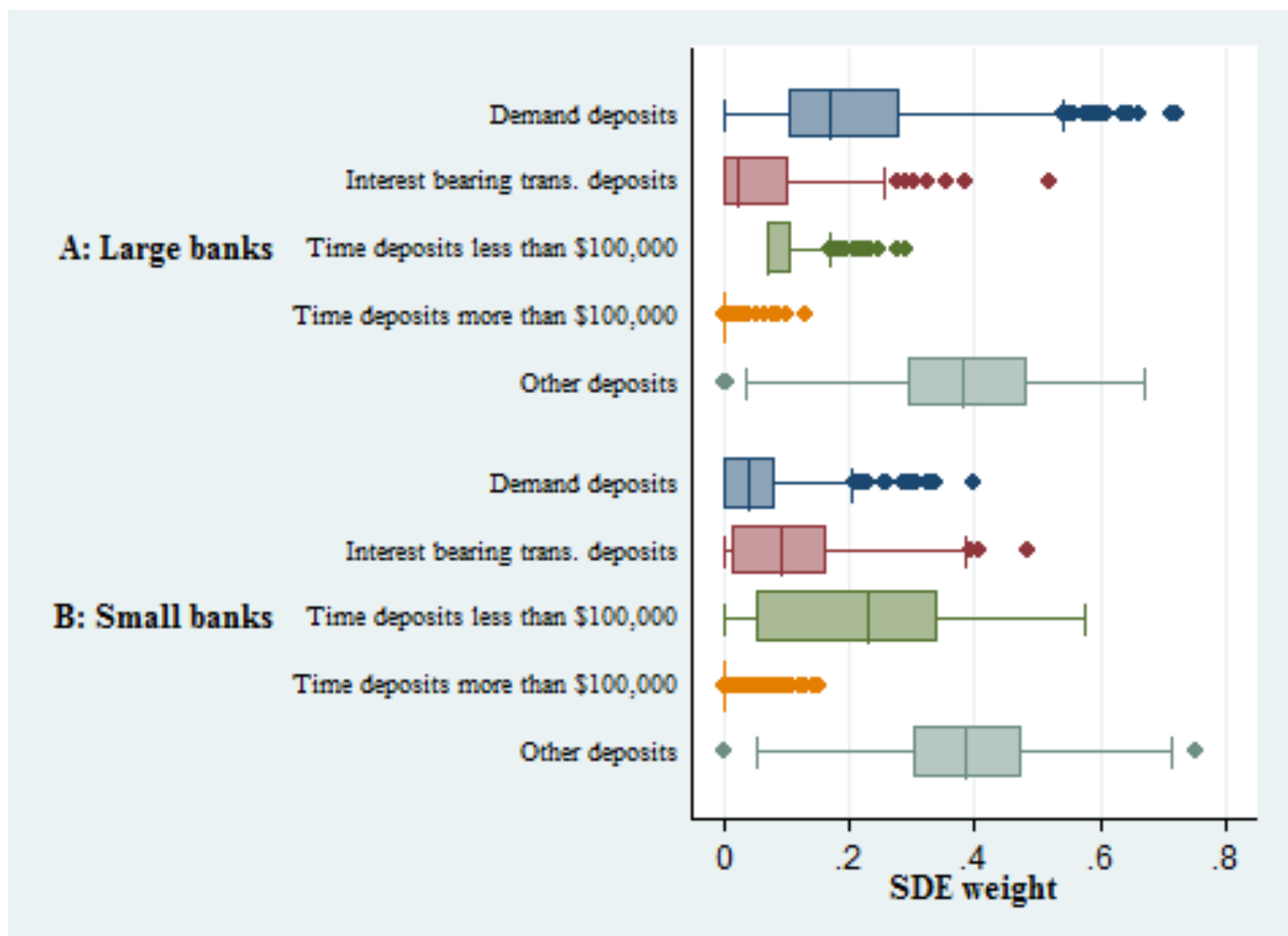

This figure shows the interquartile range of bootstrapped SDE weights for deposit classes, for large banks (Panel A) and small banks (Panel B) for the stress scenarios 2008:Q1 and 2007:Q4, respectively. The more advanced to the right the interquartile range for a given deposit class, the more funding inflows in this class tend to mitigate cash outflows from other balance sheet classes and vice versa. The bootstrapping method draws random samples with replacement from the initial data, separately for small and large banks, maintaining the same sample size as the initial sample. For each bootstrap sample we solve the optimization problem and obtain SDE weights for asset and liability classes. We repeat this procedure 300 times and derive the distribution of SDE weights each quarter. 